\title{
El nuevo reto de la contratación pública para afianzar la integridad y el control: reforzar el profesionalismo y la transparencia

\author{
ELISENDA MALARET ${ }^{1}$
}

\section{RESUMEN}

Desde febrero de 2013 la corrupción ha pasado a constituir el segundo problema para los españoles. En la medida en que la corrupción tiene una de sus principales fuentes en la mala administración relacionada con la gestión de los recursos públicos y en especial con la contratación pública, establecer medidas destinadas a prevenir o evitar las malas prácticas es una tarea esencial para el derecho administrativo. El artículo presenta algunos aspectos del proceso decisional que deberían ser rediseñados a efectos de reducir la posibilidad de evitar abusos de poder por razones relacionadas con la obtención de ventajas personales; se trata de minimizar la posibilidad de adoptar decisiones incorrectas y que persiguen ganancias personales indebidas.

Palabras clave: corrupción, gestión de recursos, contratación estatal, buena administración, malas prácticas, profesionalismo.

1 Doctora en Derecho y catedrática de Derecho Administrativo, Universidad de Barcelona Barcelona, España. Correo-e: elisenda.malaret@ub.edu Fecha de recepción: 14 de enero de 2016. Fecha de modificación: 25 de mayo de 2016. Fecha de aceptación: 31 de mayo de 2016. Para citar el artículo: Malaret, E. (2016). El nuevo reto de la contratación pública para afianzar la integridad y el control: reforzar el profesionalismo y la transparencia. Revista digital de Derecho Administrativo n. ${ }^{\circ}$ 15, primer semestre, Universidad Externado de Colombia, pp. 21-60. DOI: http://dx.doi.org/10.18601/21452946.n15.04 


\title{
New Challenges of Public Procurement: Restoring Confidence, Integrity and Control through Professionalism and Transparency
}

\begin{abstract}
As of February 2013, corruption has become the second major issue for the Spanish people. It is mainly rooted in the poor administration of public funds and especially in public procurement and therefore the need to establish means to prevent and avoid these bad practices must become an essential purpose of Administrative Law. This paper presents some aspects of the decision-making process that ought to be redesigned in order to reduce the abuse of power and personal advantage. The end goal is to minimize the possibility that the government has of adopting improper decisions and choices that seek to promote illegal personal gain.
\end{abstract}

Keywords: Corruption, Management of Public Funds, Public Procurement, Good Administration, Bad Practices, Professionalism.

\section{INTRODUCCIÓN}

En los albores del siglo XX -en un período de grandes transformaciones sociales, económicas y políticas- la corrupción fue identificada como una de las peores plagas que asolaban los gobiernos locales y estatales de Estados Unidos (con mayores responsabilidades que el gobierno federal en aquella época), en manos de maquinarias que traficaban con votos y favores y actuaban al servicio de los grandes trusts. La eclosión del periodismo de investigación y el incremento de la difusión de los periódicos crearon un amplio movimiento de denuncia frente a las injusticias sociales y los excesos mercantiles que con la corrupción política eran considerados los grandes males que amenazaban seriamente el desarrollo y el porvenir del país y socavaban la confianza ciudadana. Ante aquel panorama el movimiento progresista de los alcaldes y gobernadores reformistas de algunas grandes ciudades y algunos estados - primero, y más tarde por los presidentes Th. Roosevelt y W. Wilson- impulsó grandes cambios, introduciendo medidas para limitar el poder de las grandes corporaciones y fortalecer la toma de decisiones de las instituciones públicas, entre muchos otros aspectos.

En la esfera institucional algunas enseñanzas de aquella época pueden ser de utilidad. Las medidas adoptadas para delimitar el ámbito de decisión de los electos (políticos) y los gestores (profesionales) cobran renovada actualidad en el panorama español, y muy especialmente en el sector de la contratación 
pública. La introducción del profesionalismo -mediante la figura de los managers locales y el afianzamiento de la función pública- fue una de las apuestas relevantes (puesto que ha perdurado en el tiempo) de los paquetes de amplias reformas que en aquel entonces se adoptaron y que contemplaban un abanico de medidas de regeneración democrática y de extensión del voto.

Desde febrero de 2013 la corrupción ha pasado a constituir el segundo problema para los españoles - después del paro, que continúa siendo el principal problema y que se sitúa en un orden de magnitud muy distinto ${ }^{2}-$, si atendemos a los Barómetros que publica regularmente el $\mathrm{CIS}^{3}$. En la medida en que la corrupción tiene una de sus principales fuentes en la mala administración relacionada con la gestión de los recursos públicos, y muy en especial con la contratación pública -así como también con el urbanismo-, establecer medidas destinadas a prevenir o evitar las malas prácticas es una tarea esencial para el derecho administrativo. Es cierto que esta no es una cuestión que se dé solamente en España, y buena muestra de ello son los trabajos publicados por diferentes organizaciones internacionales. A título de ejemplo podemos recordar cómo ya en 2007 la OCDE señalaba que "la contratación pública ha sido considerada como la actividad gubernativa más vulnerable a la corrupción", y vinculaba este fenómeno a la ubicación de la contratación pública, por el hecho de estar inserta entre el sector público y el sector privado ${ }^{4}$. Las políticas de privatización de medios y recursos en distintos sectores de la actividad pública así como el creciente uso de la externalización de determinados cometidos han incrementado la relevancia e interés del tema.

La preocupación que reflejan las encuestas muestra la percepción ciudadana ante la eclosión de casos de corrupción que se han venido sucediendo los últimos años. La corrupción quizás no tiene carácter sistémico en nuestro país ${ }^{5}$, como reiteradamente ponen de manifiesto los estudios académicos y de organizaciones como Transparency International ${ }^{6}$, pero los casos han aumentado mucho desde la irrupción de la crisis; según datos de la Memoria de la Fiscalía General del Estado de 2013, los casos de corrupción aumentaron un

2 Así, a título de ejemplo, en octubre de 2013 el paro era considerado el principal problema por un $77,4 \%$ de los españoles y en diciembre de 2015 lo era para un $79,15 \%$, cuando la corrupción y el fraude se situaban en segundo lugar en la consideración de los problemas para un $31,3 \%$ de los españoles en octubre de 2013 y en diciembre de 2015 tiene esta misma consideración para un $38,8 \%$; en tercer lugar se encuentra la valoración de los problemas de índole económica -con un $32,7 \%$ y un $24,4 \%$ respectivamente-.

3 Que pueden consultarse en la web del propio Centro de Investigaciones Sociológicas: http://www.cis.es/cis/opencms/ES/11_barometros/indicadores

4 Ver OCDE (2009, p. 17).

5 Como, sin embargo se afirma en relación a Italia, en el discurso del Presidente de la Corte dei Conti en la inauguración del año judicial 2013; tomo la referencia de G. M. RACCA (2015).

6 M. Villoria. Hacia una comprensión de la corrupción en España. Working paper 1/2014 Transjus: Universidad de Barcelona. 
49,5\% desde 2007, y un año después la Memoria indica que las investigaciones por corrupción fueron el doble en 2014 que en 2013. En este entorno cabe señalar que los supuestos investigados y que han adquirido mayor notoriedad (Gürtel, caso Bárcenas, caso Millet/Palau de la Música Catalana, Instituto Noos, Palma Arena, ITV de Catalunya) tienen en su origen malas prácticas de contratación administrativa ${ }^{7}$; a diferencia de lo que había sucedido en épocas anteriores, cuando la corrupción estaba vinculada al urbanismo. Quizás no sean ajenas a este cambio de entorno sectorial las modificaciones introducidas en la legislación urbanística que han reforzado la transparencia y la trazabilidad de aquellas operaciones que en el pasado acumularon mayores patologías -como las actuaciones instrumentadas mediante convenios urbanísticos o la recalificación de terrenos-. Algunos podrán afirmar que la corrupción en la contratación ha estado siempre presente, pues a lo largo del siglo XIX la literatura y la prensa ya dieron buena cuenta de diversos casos muy notorios, pero también es cierto que el desarrollo institucional posterior parecía haber reducido estas malas prácticas.

Este trabajo no pretende examinar de manera pormenorizada los distintos procedimientos y mecanismos que pueden favorecer la creación de un entorno generador de irregularidades y malas prácticas que supongan un uso abusivo de los bienes públicos para beneficio privado. Su finalidad es más limitada, pretende presentar algunos aspectos del proceso decisional que deberían ser rediseñados a efectos de evitar abusos de poder por razones relacionadas con la obtención de ventajas personales. Se trata de minimizar la posibilidad de adoptar decisiones incorrectas y que persiguen ganancias personales indebidas.

La función del derecho administrativo de nuestro tiempo -retomando el título de un reconocido trabajo de Alejandro Nieto publicado en un momento de importantes cambios políticos, económicos y sociales ${ }^{8}$ - es tomar en consideración la complejidad social para diseñar de manera realista los procesos decisionales y los modelos organizativos que permitan adoptar las decisiones más adecuadas a la satisfacción del interés general. Este cometido de diseño institucional adquiere especial relevancia en un contexto en el que el dilema ya no se suscita en torno a la vinculación positiva a la ley, al carácter más o menos reglado de la potestad configurada por el legislador. Para que el de-

7 En esta misma dirección, la Memoria de la Oficina Antifraude de Cataluña de 2011 indica que el 29\% de los expedientes de investigación tramitados en el año de referencia tenían por objeto la contratación administrativa. Más recientemente su director ha cuestionado el sistema de licitación aplicada por la Administración de la Generalitat de Catalunya (El País, 28 de octubre de 2015).

8 La vocación del Derecho Administrativo de nuestro tiempo. RAP, 1975, 76. El autor realiza una revisión crítica de los postulados y la realidad del derecho administrativo en un momento en el que se empiezan a plantear posibles cambios del orden jurídico español. 
recho administrativo pueda continuar siendo fiel a las exigencias propias de este ámbito del saber y del derecho deberá tener en cuenta las exigencias de un mundo en transformación. Habrá de atender a la complejidad que resulta de la heterogeneidad que supone para la Administración la necesidad de satisfacer una enorme diversidad de demandas sociales -y también, económicas, culturales y democráticas- mediante la prestación de un conjunto heterogéneo de servicios públicos y la realización de una abanico de actividades, reconociendo que en el ejercicio de muchas funciones públicas no existen soluciones apriorísticas que puedan ser predeterminadas por el legislador de manera precisa, y todavía menos cuando de la obtención de recursos y de saber hacer se trata. Para que la contratación pública cumpla su cometido instrumental con eficacia y eficiencia requiere de un proceso decisorio que tenga en consideración las especificidades de los distintos momentos mediante una adecuada asignación de cometidos a diferentes órganos y mediante una adecuada publicidad de los documentos que permita posteriormente una completa rendición de cuentas.

Para que puedan abrirse camino estas reformas es preciso tomar en consideración dos elementos fundamentales que pueden parecer obvios pero que conviene recordar pues su ignorancia puede tener efectos perversos al incidir en deficientes diseños institucionales: i) la contratación pública supone movilizar los recursos económicos públicos para adquirir bienes y servicios al mercado; es una actividad de carácter económico y como tal es generadora de lucro, si bien las reglas y los procedimientos deben no sólo favorecer el funcionamiento de los mecanismos de mercado, sino garantizar que estos efectivamente funcionan para obtener resultados eficientes; ii) la obtención de bienes y servicios mediante la contratación pública supone la adopción de distintas decisiones en las que cabe, en función de los distintos momentos, o bien un espacio de libre decisión -discrecionalidad en sentido estricto-, o bien un margen de apreciación -la denominada discrecionalidad técnica-; por ello la tipología de los órganos debe ser consistente con esta realidad y adecuada a ella. Es cierto que la distinción no es compartida por toda la doctrina ${ }^{9}$, pero entendemos que la misma es pertinente para caracterizar los distintos tipos de decisiones que cabe adoptar en el ámbito de la contratación pública, el fundamento y finalidad de la tipología de decisiones, así como los distintos tipos de control judicial y los parámetros manejados para el mismo. Sin olvidar que la distinción está muy presente en la jurisprudencia española, con los efectos mencionados.

La importancia de la dimensión económica de la contratación pública es en la actualidad pacífica -esta última supone más de un 16\% del PIB de la Unión Europea-, perspectiva que también está presente en los estudios jurídicos y 
ha permitido abrir a nuevas temáticas este campo del análisis -examinando las prácticas colusorias entre empresas ${ }^{10}$, la instrumentación contractual de la innovación, las formas de colaboración público-privada ${ }^{11}$ o la realización de cometidos medioambientales y sociales mediante la contratación pública-, cuando hasta fechas recientes parecían concentrarse en aspectos formales -tipología de los procedimientos de adjudicación, ámbito de aplicación de la legislación administrativa...-, y en el pasado se habían concentrado en la naturaleza y régimen jurídico de los contratos públicos - derecho administrativo vs. derecho civil-. La irrupción del derecho europeo y el proceso de reformas a que ha sido sometido este marco legal ${ }^{12}$, así como la necesaria trasposición al sistema jurídico español de este dispositivo -y las dificultades que lo han acompañado $^{13}$, han propiciado un cambio en la perspectiva de análisis de este sector de la actividad de los poderes públicos, propiciando una eclosión de las publicaciones en materia de contratación pública, si bien todavía muy orientadas a dar cuenta de las novedades en el derecho positivo o en la jurisprudencia -muy especialmente del TJUE-; con algunas salvedades notables en materia de concesiones de obra pública donde el recurso a la metodología del análisis económico del derecho ha propiciado estudios notables -evidenciando algunas patologías en la instrumentacion del ius variandi- ${ }^{14}$, a la vez que ha permitido ilustrar las carencias del enfoque tradicional y la necesidad de proceder a un análisis riguroso de las prácticas contractuales que permita superar las limitaciones de un positivismo que se limita a dar cuenta de la obra del

10 Ver La Guía sobre contratación pública y competencia, publicada por la antigua Comisión Nacional de la Competencia (2010), de la que dieron cuenta B. Lozano Cutanda y J. E Soriano (2011, pp. 48 ss).

11 Ver, por todos, M. HeRnANDO RYDINGS. La colaboración público privada. Fórmulas contractuales. Madrid: Thomson Reuters/Civitas, 2012, especialmente pp. 375 ss.

12 Inicialmente se adoptaron cuatro directivas (92/50/CEE, 93/36/CEE, 93/37/CEE y 93/38/CEE), posteriormente las reglas establecidas en las directivas de contratos públicos de obras, servicios y suministros se fusionaron en aras de una mayor simplificación y clarificación mediante la adopción de la Directiva 2004/18/CE sobre los contratos públicos de obras, suministros y servicios - modificada por la Directiva 2005/75/CE-, quedando al margen solamente los contratos relativos a aquellos sectores que anteriormente habían sido ya excluidos de las directivas sectoriales - puesto que se trataba de contratos realizados generalmente por empresa públicas en determinados sectores en los que la competencia era escasa o inexistente, como aguas, transportes, servicios postales o energía- y que fueron objeto de una nueva directiva (2004/17/CE); finalmente la Directiva 2009/81/CE introdujo reglas específicas para los contratos públicos en el sector de la defensa.

13 De la que dan muestra las reiteradas condenas a España por su deficiente transposición del derecho europeo, incumplimientos que han afectado muy especialmente la vertiente subjetiva del ámbito de aplicación, ver, en particular, las sentencias del TJCE de 15 de mayo de 2003 y de 13 de enero de 2005.

Ver, especialmente, A. Ruiz OJEDA (2006). 
legislador y de las aportaciones de la jurisprudencia en la tarea de determinar la interpretación del alcance de una regla legal.

Dado el impacto económico de la contratación pública y el volumen de los recursos económicos que se manejan, cobra especial significación práctica el objetivo de evitar que tanto los actores del sector público como los del sector privado que intervienen en el proceso desvíen en su propio interés fondos públicos. En esta dirección de prevenir los conflictos de intereses, los remedios son ampliamente compartidos y podemos encontrarlos diseñados en distintos instrumentos puestos a punto por organismos internacionales -OCDE, BM, OMC-y también por las instituciones de la Unión Europea ${ }^{15}$. Dos orientaciones emergen con fuerza en este cuadro: i) fomentar y ampliar la transparencia para garantizar la información y la participación del más amplio número de operadores y en consecuencia favorecer la competencia efectiva, y ii) incentivar e incrementar el profesionalismo.

En la medida en que posteriomente nos ocuparemos con más detenimiento de algunas cuestiones planteadas por la exigencia de reforzar el profesionalismo, avanzamos ahora que la información pública, la obligación de actuar de manera transparente y suministrar una información lo más completa posible alcanza a todas las fases del proceso de contratación, esto es: a) en la fase previa, mediante la necesaria publicación de alertas y avisos de los calendarios y supuestos de las futuras licitaciones -formulando planes anuales-; b) durante todo el proceso de licitación y adjudicación -este es el aspecto tradicionalmente mejor resuelto, aunque se detectan algunas lagunas, en especial en relación con el alcance y contenido de la decisión final, así en cuanto a la publicidad del contrato-; y c) en las fases posteriores de ejecución y liquidación -en las que se detectan carencias en relación con el alcance de las modificaciones que afectan al objeto y al sujeto, así como en lo que atañe a las revisiones de precio y a la práctica de las liquidaciones finales-. Una publicidad especialmente necesaria en la medida que posibilita el control por los otros operadores económicos -que quieran o hayan participado o no en el proceso en cuestión- y por la ciudadanía en general. La publicidad de los documentos, de la información en manos de la Administración Pública no debe entenderse como un ejercicio de "voyeurismo" 16 , como una mera respuesta a la creciente desconfianza en las instituciones ${ }^{17}$ (de nuevo consideradas al servicio del poder financiero), sino como una herramienta fundamental para ilustrar e incrementar el conocimiento necesario para garantizar el control social, el control por parte de la comunidad; se trata de promover la mayor transparencia cuando se 
adoptan los procedimientos de adjudicación -más o menos competitivos ${ }^{18}-\mathrm{y}$ posteriormente, durante la vida del contrato, cuando surjan litigios entre las partes. Por ello es pertinente diseñar detenidamente las instituciones adecuadas a esta finalidad inherente al Estado social y democrático de derecho que la Constitución española sanciona (art. 1.1).

Partiendo del estado actual del derecho positivo español, este trabajo tiene por objeto aportar elementos de debate acerca de la necesidad de acometer algunas reformas legales destinadas a incrementar la calidad del proceso decisorio en materia de contratación pública. Entendemos que este aspecto no ha sido objeto de consideración suficiente por razones que atañen a la concepción dominante en la ciencia del derecho administrativo y que hunden sus raíces en el paradigma que alumbró su reconstrucción a partir de la década de 1950: una visión que ha hipertrofiado la idea de la lucha contra las inmunidades del poder, impidiendo la correcta delimitación de los espacios de libre decisión, muy en especial de aquellos que necesariamente requerían un margen de libre apreciación. La negación de esta realidad, imprescindible para la determinación del interés general y la eficiente asignación de los recursos públicos, la obsesión por configurar todo ámbito decisorio como reglado, han supuesto serias trabas para abordar de manera coherente y adecuada a la finalidad de la tarea encomendada la correcta delimitación de funciones entre los órganos de naturaleza política -dotados de legitimitad democrática-y los órganos de naturaleza técnica -dotados de legitimidad profesional-.

Sólo a partir del reconocimiento de que en el ámbito de la contratación pública existen espacios en los que la discrecionalidad administrativa -o una cierta libertad decisional- es pertinente (pues responden al ejercicio de la capacidad de decidir entre distintas opciones o maneras de satisfacer el interés general), ámbitos que las recientes directivas han incrementado ${ }^{19}$ y también ámbitos en los que necesariamente hay que reconocer un margen de apreciación -que tradicionalmente se ha denominado discrecionalidad técnica-, y de que ambos supuestos son susceptibles de un control jurisdiccional limitado, será posible introducir reformas destinadas a garantizar efectiva y eficazmente la integridad. Por ello las garantías deben construirse diseñando un procedi-

Puesto que en aquellos supuestos en los que las cantidades en juego sean menores no existirá un procedimiento efectivamente competitivo porque cabe la adjudicación directa -art. 138.3 TRLCSP-, lo que no debe excluir la transparencia pues esta es garantía de que se respete otro principio esencial de la contratación pública, la igualdad, que en este caso supone que no puedan adjudicarse a una única empresa todos los contratos menores equivalentes.

19 Como expresamente reconoce el Informe ASTRID (2015); este documento, publicado por la prestigiosa organización que agrupa a eminentes académicos y altos funcionarios italianos, ha sido dirigido por A. PAJNO (recientemente nombrado presidente del Consiglio di Stato, el más alto tribunal administrativo -en un sistema dual como el italiano-) y L. TORCHIA, accesible en la página web de la institución. 
miento adecuado, con una tipificación de los órganos intervinientes apropiada e imponiendo una carga de justificación/motivación precisa, así como unas obligaciones de publicidad lo más amplias posibles -sólo limitadas por el respeto a la privacidad y el secreto comercial, así como por la preservación de la eficiencia en el proceso decisional y por la efectividad de la competencia entre operadores-.

\section{LA CONTRATACIÓN PÚBLICA EN EL DERECHO ADMINISTRATIVO ESPAÑOL, UN CAMINO HACIA EL RECONOCIMIENTO DE LA RELEVANCIA DEL PROCESO DECISIONAL. UN BREVE APUNTE SOBRE EL CAMBIO DE PARADIGMA EN CURSO, DEL CONTRATO ADMINISTRATIVO A LAS COMPRAS PÚBLICAS}

Desde sus inicios la ciencia del derecho administrativo ha centrado su atención en la naturaleza jurídica de la institución del contrato administrativo; se trataba de examinar cuáles eran las razones que justificaban que el contrato en el que era parte la Administración Pública tuviera un régimen jurídico distinto, y en su caso, la jurisdicción competente también fuera la administrativa y no el juez ordinario ${ }^{20}$. En esta perspectiva cobran toda la relevancia los poderes de la Administración, y emerge una concepción de la contratación pública focalizada en el contrato administrativo, un contrato en el que la Administración ejerce prerrogativas en la ejecución del contrato -interpretación y modificación-y en su resolución ${ }^{21}$.

Si bien en las primeras reglamentaciones de la contratación pública, centradas en el ámbito de la construcción de equipamientos e infraestructuras, el objeto de la legislación era el establecimiento de una tipología de contratos que tenía por objeto la obra pública, contratos que se diferenciaban por la forma de remuneración del contratista ${ }^{22}$, la principal preocupación-como es fácil de imaginar- era la financiera ${ }^{23}$. Es precisamente en este ámbito de la actividad y dado que la Administración no realizaba normalmente las obras por ella misma, donde surgió la figura del contrato administrativo ${ }^{24}$. Una institución afianzada cuando los conflictos entre Administración Pública y empresas derivados de las controversias surgidas con ocasión de la ejecución de francés, ver por todos R. PARADA (1963).

21 E. Malaret (1997).

22 F. J. JiMÉNEZ dE CiSNEROS (1998).

23 E. Malaret. Financiación e infraestructuras de las televisiones (2003, pp. 73-102).

24 S. MARTín-RETORTILlO (1960). 
los contratos obligaron a plantearse la cuestión del carácter de los contratos y el alcance de las prerrogativas ${ }^{25}$.

En la búsqueda de la limitación de unos poderes considerados exorbitantes, acotándolos en su ejercicio frente a las empresas privadas mediante la introducción de garantías que aseguren que si no hay acuerdo deba necesariamente intervenir otra instancia externa (el Consejo de Estado) ${ }^{26-27}$, se perdió por el camino el necesario equilibrio que debe existir entre el interés general -que legitima ciertamente su atribución, pero también su ejercicio concreto, y muy especialmente establece los límites de su instrumentación en relación con los supuestos de hecho precisos-, así como la protección de los derechos de las empresas -reforzada por la construcción de la teoría del equilibrio financiero del contrato-. Dos vectores han condicionado la dinámica de la vida del contrato: uno de carácter práctico y otro de carácter más teórico. Así, no pueden ignorarse los costes en términos de dificultades en la gestión y de tiempo (retrasos) que para la Administración supone la rescisión del contrato (se produce una especie de "captura" por parte del adjudicatario), pero tampoco puede desconocerse el peso de la construcción teórica elaborada para fundamentar la posibilidad de modificar unilateralmente el objeto del contrato; esto es el principio de la inalterabilidad del fin que justifica la mutabilidad del objeto (siempre que se respete la equivalencia económica de la prestación). De tal manera que la ampliación del contrato (en cuanto al objeto o ámbito material o en cuanto al plazo) operaba como una suerte de "lotería" para la empresa contratista, al no producirse una nueva licitación, en detrimento de la eficiente asignación de los recursos públicos ${ }^{28}$, pues un contrato adjudicado por un precio y para un tiempo determinado se veía prorrogado o ampliado en su objeto, con las consiguientes contraprestaciones en términos de remuneración (que sólo habían pasado por el cedazo de la negociación bilateral, sin el contrapunto del escrutinio competitivo).

El análisis de la práctica contractual evidenciaba lo que podriamos convenir en caracterizar como la naturalidad (o la rutina) de las modificaciones de los contratos con posterioridad a su adjudicación, sin que se pusiera en duda que dicha dinámica suponía un cuestionamiento claro de las bases que habían presidido la adjudicación inicial. Este modo de proceder generaba un efecto

25 R. FERNÁNDEZ DE VeLASCO. Los contratos administrativos. Madrid: Librería general de Victoriano Suárez, 1927.

26 Sobre la resolución ver, especialmente, C. BARRERO RODRíGUEZ. La resolución de los contratos administrativos por incumplimiento del contratista. Valladolid: Lex Nova, 2007.

27 Sobre el ius variandi ver, por todos, C. HORGUÉ BAENA. La modificación del contrato administrativo de obra. Madrid: Marcial Pons, 1997.

28 Ver, en especial, J. M. BAÑo. Del ius variandi a la libre concurrencia: la prohibición de modificación como regla general de los contratos públicos. Anuario de Gobierno Local 2012. Barcelona: IDP, 2013. 
anti competitivo claro puesto que la significación de la oferta como elemento clave en la adjudicación quedaba desvalorizada ya que con posterioridad esta se podía ver alterada por petición de la empresa o a instancias de la propia Administración (y por ello la Comisión Europea ha obligado a modificar la legislación española ${ }^{29}$ ). Una práctica de modificación de los contratos que en determinados campos adquirió carta de normalidad mediante la modificación de la legislación sectorial (cuando los tribunales empezaron a cuestionar esta política se recurrió a la construcción de la habilitación ex lege), como en el supuesto de las autopistas de peaje ${ }^{30}$. De nuevo, el derecho europeo obliga a cambiar la perspectiva, la aprobación de la Directiva 2014/23/UE ha enfatizado la idea del "riesgo operacional" y ha reforzado la importancia de la asunción de riesgos por parte del concesionario -como elemento característico de esta tipología de contratos-. Ya anteriormente, la Sentencia TJUE de 22 de abril de 2010, por la que se declaró el incumplimiento de la Directiva de obras de 1993 por la adjudicación de obras complementarias a una concesionaria sin que estuvieran comprendidas en el objeto de la concesión, provocando la vulneración del principio de igualdad de trato, propició la aprobación de una reglamentación más restrictiva en relación con las autopistas de peaje ${ }^{31}$.

Por ello no sorprende que según los datos del Eurobarómetro de la Comisión Europea Businesses attitudes towards corruption in the EU, 2014, España es el país en el que es mayor la percepción de que la modificación de los contratos públicos está muy extendida (69\%), muy lejos de la media europea (44\%) y de Finlandia $(18 \%)$; como hemos indicado, esto significa que las reglas del juego a través de las cuales se ha licitado un contrato, en función de las cuales las empresas candidatas han presentado sus ofertas, se cambian una vez que el contrato entra en fase de ejecución. A veces se relaciona la excesiva generalización de esta práctica con la deficiente planificación o con las prisas en la gestación a fin de obtener rédito electoral (especialmente en la obra pública) ${ }^{32}$, con la aceptación de bajas temerarias (que de entrada pueden aparecer como ahorros o ganancias para las arcas públicas) o también, pura y simplemente, con la admisión de sobrecostes derivados directamente de pagos o dádivas, esto es, de corrupción.

29 Como señalaba expresamente la reforma de la LCSP introducida por la Ley de Economía Sostenible (2011), en cuya exposición de motivos se hacía referencia expresa a las prácticas recomendadas por la Comisión Europea.

30 V. un análisis muy exhaustivo en Ruiz OJedA (2006).

31 V. RD 488/2012, de 5 de marzo, por el que se modifica el Decreto 215/1973, que aprobaba el pliego de cláusulas generales en materia de autopistas en régimen de concesión, limitando las modificaciones admisibles.

32 L. MARTín RebOlLO recuerda una vieja máxima de la contratación (que tiene su origen en la primera legislación de contratación pública): "gestación lenta y ejecución rápida", en (2015). 
Por el contrario, la perspectiva del derecho europeo de la contratación pública es distinta. En efecto, el marco legal europeo se construye sobre unas bases diferentes pues el fundamento de las competencias de las instituciones europeas está directamente orientado a la garantía del mercado interior; en consecuencia la perspectiva de la garantía de la competencia, de la libertad de establecimiento y la libre circulación de mercancías y servicios, así como los principios que se derivan de estos -como la igualdad de trato, la transparencia, la proporcionalidad o el reconocimiento mutuo-, constituyeron los objetivos de las directivas desde los primeros momentos ${ }^{33}$. La aproximación del derecho europeo no responde sólo a la idea de preservar la correcta gestión de los caudales públicos y la disminución del gasto inherente a la misma, presente en los derechos nacionales y origen de las reglamentaciones específicas de la contratación pública, el objetivo europeo era y es abrir los mercados "nacionales" a la competencia de todas las empresas europeas, esto es, contribuir a la eficiencia en la asignación de recursos al mejorar la competencia. Era y es una perspectiva de oferta; una concepción de la contratación pública muy económica y quizás menos "presupuestaria" -aunque tampoco puede ignorarse el papel que históricamente han supuesto las compras públicas en la promoción de la industria nacional.

En este contexto el contenido de las disposiciones europeas se orientó a la fijación de las reglas y principios relativos al procedimiento ${ }^{34}{ }_{i}$ las condiciones establecidas debían asegurar que la formación de la voluntad de la Administración Pública garantice el interés general, así como el respeto a las libertades y al principio de no discriminación por razón de la nacionalidad establecidos en los Tratados. En consecuencia, es un derecho focalizado en la licitación y la adjudicación ${ }^{35}$. Precisamente para garantizar la efectividad de la competencia y de las reglas a su servicio -igualdad y publicidad--, el derecho europeo (en una fase posterior) impulsó el control y la tutela judicial mediante la introducción de recursos contractuales. Y, en esta misma dirección, progresivamente ha ampliado su ámbito intoduciendo reglas relativas a la ejecución, en la medida en que determinadas prácticas nacionales podían desnaturalizar las reglas de adjudicación, estableciendo de manera restrictiva las condiciones y límites del ejercicio del ius variandi, así como las reglas en materia de subcontratación (para favorecer el acceso de las pyme), o los requisitos que deben guiar la introducción de cláusulas sociales y medioambientales ${ }^{36}$. Precisamente se trata

Ver el considerando 1 de la última directiva, la 2014/24/UE del Parlamento y del Consejo, de 26 de febrero de 2014, por la que se deroga la Directiva 2004/18/CE.

34 Aunque se intitularan las directivas bajo la rúbrica de la coordinación, en atención al principio de subsidiariedad que estructura la distribución de competencias entre la Unión Europea y los Estados miembros

35 Ver, especialmente, S. Dí́zZ SASTRE (2012).

36 Sobre el contenido de las últimas modificaciones, ver J. M. GimEno Feliú (2014). 
de aquellos aspectos que tradicionalmente no habían sido objeto de atención -o de una atención escasa- por el derecho administrativo español, aunque la disciplina del gasto público había inducido la adopción de disposiciones en materia de procedimientos de adjudicación -diferenciando entre los supuestos de subasta, concurso y adjudicación directa-y así, en la actualidad el régimen jurídico de los contratos administrativos, tanto en cuanto a su preparación como en cuanto a su adjudicación, efectos y extinción, se rige por la legislación de contratos públicos y el derecho administrativo ${ }^{37}$.

Los contratos públicos constituyen el ámbito del derecho europeo, esto es, los contratos celebrados por una Administración Pública (en sentido amplio) ${ }^{38}$ a título oneroso y cuyo objeto sea la adquisición de bienes o servicios o la realización de obras, con independencia de la naturaleza jurídica de los mismos (pues esta es una cuestión que corresponde determinar a los derechos nacionales). La noción de contratos públicos no es en ningún caso equivalente con la institución del contrato administrativo presente en el ordenamiento jurídico español, aunque en determinados supuestos el ámbito pueda superponerse. Desde la vertiente subjetiva cubre una realidad más amplia, puesto que afecta también a contratos celebrados por entidades que no tienen el carácter de Administraciones públicas ${ }^{39} \mathrm{y}$, por el contrario, desde la vertiente objetiva es más limitada, en la medida en que sólo contempla los contratos que tengan por objeto la ejecución de obras, la adquisición de suministros y la adquisición de servicios ${ }^{40}$-los contratos de servicios se incorporaron a la legislación administrativa española con ocasión de la primera transposición de la directiva sectorial en este ámbito-; pero, en cambio, tanto las concesiones de obras públicas ${ }^{41}$ como las de servicios públicos quedaban fuera de la noción de contratos públicos y eran objeto de una marco legal diferente -menos denso-, aunque, en todo caso, su adjudicación debía respetar los principios del Tratado de Funcionamiento de la Unión Europea -libertad de circulación y de establecimiento, no discriminación, transparencia, igualdad de trato- ${ }^{42}$. Por el contrario, el ordenamiento jurídico español establece que tendrán el

37 Art. 19.3 del Texto refundido de la Ley de Contratos del Sector Público (en adelante, TRLCSP).

38 Por ello se construye la noción comunitaria de "poder adjudicador" y de "organismo de derecho público"; , ver el artículo 2.1 y 4 de la actual directiva en vigor -y pendiente de transposición en el derecho español-, la 2014/24/UE, que no introduce novedades en este ámbito.

Ver art. 3 TRLCSP.

40 Los objetos de estos contratos también son definidos; ver el artículo 2.6 a 9 de la actual directiva en vigor -y pendiente de transposición en el derecho español-, la 2014/24/UE, que no introduce novedades en este ámbito.

41 Aunque la Directiva 89/440/CEE sobre contratos públicos de obras las incorporó al texto de la directiva, pero contemplando un régimen menos denso.

42 Ver la actual Directiva 2014/23/uE del Parlamento Europeo y del Consejo, de 26 de febrero 
carácter de contrato administrativo también las concesiones de obras públicas y de servicios, así como los contratos de colaboración público-privada ${ }^{43}$.

La noción de contratos públicos encuentra su equivalente en la categoría de los "marchés publics" del derecho administrativo francés, pero superando el criterio orgánico restrictivo ${ }^{44}$ propio de la tradición en que se inscribe dicho sistema jurídico; una perspectiva semejante encontramos en los modelos de "public procurement". Modelos en los que la perspectiva de la eficacia y la eficiencia en el gasto público va acompañada de la consideración de la función que desempeña la contratación pública en la realización de las políticas públicas, de su carácter complementario o instrumental para el desarrollo de políticas sociales - parados de larga duración, colectivos vulnerables, salarios dignos...-, medioambientales, de apoyo a la innovación o de fomento de las pymes. Y en esta perspectiva, la delimitación precisa de las necesidades, la correcta elección del procedimiento y, muy especialmente, la adecuada selección de los criterios de adjudicación constituyen elementos fundamentales para la realización de los objetivos, unos fines para los que la correcta asignación de los recursos es fundamental, por lo cual la garantía de la concurrencia es estratégica. La publicidad y la competencia no son fines en sí mismos -son corolario de la libertad de circulación y establecimiento, de la igualdad de trato y de la no discriminación por razón de la nacionalidad-, pero son condiciones esenciales para el correcto cumplimiento del interés general en la contratación. En este sentido cabe señalar que el derecho europeo está orientado a la tutela y protección de los derechos de los licitadores ${ }^{45}$, en tanto en ello estriba el correcto funcionamiento del mercado -y no tanto a la garantía del contratista, que era por el contrario el planteamiento tradicional en el derecho administrativo español, que privilegiaba la posición del contratista mediante el denominado principio del equilibrio económico del contrato, construido como el reverso de la mutación del objeto del contrato como consecuencia del ius variandi ${ }^{46}$.

La noción de compras públicas pretende enfatizar la posición que tiene la Administración -y no tanto la forma en que compra, mediante el contrato-, identificando su posición precisamente en el mercado, una posición que obliga a introducir el tema de la competencia; si no operase en el mercado,

de 2014, relativa a la adjudicación de los contratos de concesión, si bien hasta la fecha las concesiones de obras públicas se regían por la Directiva 2004/18.

Art. 19.1.a TRLCSP.

Aunque el primer intento de establecer un marco legal común, mediante la Directiva 71/305/ CEE sobre obras y la Directiva 77/62/CEE sobre suministros, respondía a una concepción del ámbito subjetivo de carácter más restrictiva pues sólo se aplicaban a las Administraciones públicas con un estatus de derecho público.

Como destaca acertadamente Gallego CórColes (2015).

Ver una presentación de esta construcción clásica en el tratado más importante de la disciplina, GARCÍA DE ENTERRÍA y FERNÁNDEZ RodríGUEZ (2008), aunque la última edición $\left(14 .^{\mathrm{a}}\right)$ le dedica menos espacio. 
no tendría ningún sentido introducir la cuestión del derecho de la competen$\mathrm{cia}^{47}$. Es cierto que el derecho de la competencia se originó para ser aplicado sólo a las empresas, pero no podemos olvidar que desde el primer momento el derecho europeo de la contratación pública surge precisamente para abrir la actividad de las Administraciones públicas nacionales a la competencia europea, favoreciendo la creación de un mercado de compras públicas. Pues cuando la Administración compra, con ello delimita un mercado de referencia, mediante la formulación de los correspondientes pliegos de condiciones u otros documentos que se utilicen.

La importancia de la preparación y la adjudicación tiene su complemento -necesario e imprescindible- en la articulación de mecanismos específicos de tutela y control que fueron introducidos por la denominada Directiva recursos (1989, modificada luego en 1992 y completada posteriormente por la Directiva 2007/66) y que en el orden jurídico español ha supuesto la introducción de un recurso administrativo especial, así como la creación de los tribunales administrativos de recursos contractuales configurados con un estatus que tiene como finalidad esencial garantizar su independencia ${ }^{48}$.

Vemos pues cómo las características y la extensión de la legislación de contratos públicos han sido objeto de profundos cambios con el tiempo, impulsados por la necesidad de incorporar el derecho europeo y las finalidades propias de este orden jurídico.

Podemos ahora sintetizar las líneas de evolución en el período más reciente. A grandes rasgos el derecho administrativo de la contratación pública en España ha ido ampliando su ámbito subjetivo y objetivo con las fases más significativas que indicamos a continuación: i) de la Ley de Contratos del Estado $\left(1965^{[49]}\right)$, pasando por la Ley de Contratos de las Administraciones Públicas, a la Ley de Contratos del Sector Público (2007); ii) de una legislación general muy orientada a la obra pública -y sólo con algunas reglas básicas en materia de contratos de gestión de servicios públicos y suministros- (LCE, 1965), pasando por el desarrollo del régimen de los contratos de suministros y la incorporación plena de los contratos de servicios (LCAP, 2005), a la incorporación de los contratos de colaboración público-privada y a la integración de los contratos de obras, suministros y servicios de carácter privado pero sujetos a una regulación armonizada -por razón de la naturaleza de la organización que los celebra- (LCSP, 2007).

Sin embargo un ámbito se ha mantenido ajeno a este proceso de expansión de la legislación general: el de los contratos de gestión de servicios públicos, en el que las leyes sectoriales tienen mayor relevancia $-\mathrm{y}$ a las que se remite 
expresamente la legislación general desde la LCE (1965)-, sin que el aumento del recurso a los operadores privados en determinados sectores relevantes de las tareas públicas haya modificado esta tendencia. En efecto, tanto en las comunidades autónomas como en las Administraciones locales, la encomienda de la gestión de servicios públicos como la sanidad -hospitales, centros de atención primaria- o la educación o los servicios sociales a entidades privadas -lucrativas o no- es una realidad. Y sin embargo, esta "privatización" o "externalización" de la gestión no se ha visto acompañada de una mayor regulación de estos contratos, ni de un incremento de su tipología para responder a la diversidad de situaciones, sino que continúa la escasa densidad normativa (sólo 15 artículos del TRLCSP tienen por objeto específico la contratación de servicios públicos); una política legislativa que hunde sus raíces en la LCE (1965), en una época en la que las Administraciones no prestaban casi servicios públicos. Una débil reglamentación de los contratos de servicios públicos que ahora se ha visto amplificada por el dato del pluralismo legislativo inherente al Estado autonómico puesto que la TRLCSP tiene el carácter de legislación básica ${ }^{50}$, lo que supone que las comunidades autónomas deberían dictar las leyes de desarrollo; si bien lo cierto es que muy pocas han utilizado esta competencia legislativa, y las pocas que han aprobado leyes de contratación pública han "retomado" los mismos criterios que la legislación básica (quizás con algunas salvedades en relación con la configuración del Tribunal de recursos contractuales ${ }^{51}$ y con la introducción de las denominadas cláusulas sociales y medioambientales-adoptadas al amparo del derecho europeo de la contratación pública ${ }^{52}$ ).

Ahora bien, a pesar de estas transformaciones continúan existiendo deficiencias. La paradoja del sistema jurídico español estriba en que las insuficiencias del marco legal actual se producen en un ordenamiento jurídico caracterizado por la existencia de la institución del contrato administrativo, por una tradición de legislación administrativa de contratos, pero este marco legal no ha sido desarrollado de manera paralela y en consonancia con el crecimiento de las tareas públicas derivadas de la garantía de los derechos y libertades constitucionales y del desarrollo del Estado de bienestar.

También es cierto que esta carencia, que como hemos visto es especialmente significativa en el contexto de los contratos de gestión de servicios públicos $^{53}$, no se ha visto hasta la fecha cuestionada ni desde el ámbito académico ni desde otras instancias. A pesar de que supone mayores espacios de discrecionalidad tanto en la vertiente organizativa como en la determinación

50 Aunque no toda, de acuerdo con lo establecido en su Disposición Final Segunda, apartado tercero.

51 Cuyas normas básicas están establecidas en el artículo 41.3 TRLCSP.

52 Como por ejemplo la Ley 3/2016, de 7 de abril, del País Vasco, para la inclusión de determinadas cláusulas sociales en la contratación pública. 
del régimen de prestación de los servicios (en lo que respecta a la vez a las obligaciones de los operadores privados y a los derechos de los usuarios). Quizás porque los servicios públicos, a pesar de su importancia creciente en el conjunto de cometidos de las distintas Administraciones públicas a partir del período constitucional, así como su peso en el PIB de la economía española, no han tenido nunca ni tienen todavía ahora una posición preferente en la Ciencia del Derecho Administrativo español ${ }^{54}$-como un breve repaso a los distintos manuales de la disciplina ilustra-.

En el paisaje de los estudios y análisis tampoco abundan los libros blancos, ni sobre la corrupción ni sobre la contratación pública, y los informes de los tribunales de cuentas sólo en tiempos recientes han empezado a examinar con cierto detenimiento algunos expedientes relevantes (contratación del Ave Madrid-Barcelona, Fondo estatal de inversión local -plan E, contratación de las comunidades autónomas), detectando una deficiente aplicación de la legislación de contratación pública: débil o inexistente justificación de las necesidades o de la elección del procedimiento, nula justificación de la adopción de unos determinados criterios de adjudicación, fraccionamientos indebidos para evitar la aplicación de procedimientos de adjudicación más abiertos y competitivos, abusos en la tramitación de urgencia, desviaciones de precios... Un catálogo de incumplimientos que coincide con las malas prácticas reseñadas en el texto de la OCDE anteriormente citado.

\section{PARA REFORZAR LA INTEGRIDAD E INCREMENTAR EL PROFESIONALISMO HAY QUE REDISEÑAR LAS ESTRUCTURAS ORGANIZATIVAS Y ADECUAR LA TIPOLOGÍA DE LOS ÓRGANOS A SUS RESPECTIVOS COMETIDOS}

Tradicionalmente el debate acerca de las malas prácticas y la corrupción re lacionadas con la contratación pública se ha centrado en unos aspectos muy puntuales: i) la necesidad de acotar y delimitar las condiciones que posibilitan la adjudicación directa - y mejorar su control-, ii) evitar la adjudicación mediante pliegos hechos a medida para uno de los candidatos y, como ya hemos indicado reiteradamente, iii) la modificación de los contratos. Aparte de la necesidad de delimitar mejor las condiciones y requisitos para adoptar las decisiones relativas a los supuestos indicados ${ }^{55}$, los remedios se han concentrado en incorporar más y mejores prácticas para acrecentar la transparencia ${ }^{56}$ en 
todas sus vertientes y en las distintas facetas del procedimiento - preservando, obviamente, la confidencialidad de las ofertas, pues es esencial para el correcto funcionamiento de la competencia-.

Si tomamos en consideración los casos de corrupción que han ido aflorando los últimos años vemos que esta aproximación no es suficiente. Por ello nosotros pretendemos centrarnos en una cuestión distinta, la necesidad de reforzar la capacitación y el profesionalismo como instrumento al servicio de la integridad ${ }_{i}$ ello requiere rediseñar los órganos que intervienen a lo largo del procedimiento, delimitar sus funciones adecuadamente y proceder a determinar la esfera que corresponde a unos y otros órganos en función de la tipología y naturaleza de las decisiones a adoptar.

Reforzar el profesionalismo supone dotar de mayor capacitación y saber a las instancias que deben intervenir necesariamente -esto es, aquellas que deberán realizar por sí mismas la valoración y apreciación de las propuestas formuladas por las empresas ofertantes, sin que el recurso a empresas especializadas pueda suponer en ningún caso que el órgano pueda simplemente remitirse a la valoración efectuada por terceros ${ }^{57}$. Ello no supone que todos los órganos deban estar regidos por las mismas reglas en cuanto a la composición y tipología de sus miembros. La designación de los titulares de los órganos que realizan determinados cometidos por criterios de mérito y de capacidad parte del reconocimiento, o mejor presupone, que otras instancias tienen una composición distinta. Esta proposición de reforma organizativa parte de la distinción entre política y técnica que es inherente a la distinción entre Gobierno y Administración, entre cargos electos o de designación política y nombramientos basados en los principios de mérito, capacidad e idoneidad ${ }^{58}$. Una distinción que si bien presenta zonas de incertidumbre proporciona también unos criterios de organización y distribución de tareas presentes en la mayoría de sistemas jurídicos de nuestro entorno; está en la base de toda la jurisprudencia constitucional italiana sobre los nombramientos de la "dirigenza" o directivos profesionales.

Este aspecto, en la medida en que atañe a la organización administrativa (hasta hace unos años, "reducto" de las competencias "nacionales", aunque desde hace mucho tiempo el procedimiento y la organización han dejado de ser materias ajenas al derecho europeo), no ha sido abordado hasta la fecha en el derecho europeo de la contratación pública. Si bien, y de manera indirecta, se ha abierto algún resquicio a partir de la Directiva de recursos y de las

Ver STS de 17 de diciembre de 2012, que anula una adjudicación por insuficiencia de motivación al no haber existido una apreciación propia por parte de la mesa de contratación, el órgano que debe efectuar la valoración de las ofertas de los licitadores y la propuesta de adjudicación.

Ver, por todos, R. JIMÉNEZ ASENSIO (1992, p. 32). 
exigencias establecidas en relación con la composición de los tribunales que deberán resolverlos ${ }^{59}$.

Ello supone entender todo el ciclo de la contratación como un proceso completo, con distintas fases, aunque éstas no tienen por qué ser impulsadas y gestionadas por el mismo órgano. Si atendemos a los principios constitucionales de la organización administrativa, de los que se infiere la necesaria adecuación de las características y tipología de cada organización a las potestades y a los cometidos concretamente asignados por el legislador, podemos considerar que no se cumple el principio de adecuación puesto que, con independencia de las tareas concretas, la legislación establece la existencia de un único órgano de contratación al que asigna todas las competencias que suponen poder decisorio, sin perjuicio de la existencia de órganos de asistencia.

La Constitución de 1978 estableció la distinción entre Gobierno y Administración -el Gobierno dirige a la Administración y esta se encuentra sometida a unos principios fundamentales-, y si es cierto que ello no supone una radical separación, también lo es que no cabe la confusión de tareas puesto que la legitimidad de una y otra es distinta y la composición de sus órganos debe corresponder a esta realidad.

La tradicional dicotomía Gobierno versus Administración va acompañada del par legitimidad democrática -que supone una amplia discrecionalidad, la capacidad de elegir la mejor satisfacción del interés general-versus legitimidad tecnocrática -con la consiguiente reducción del ámbito de libre decisión a lo que es un margen de apreciación basado en criterios técnicos o propios de un saber profesional, la denominada discrecionalidad técnica- ${ }^{60}$. Esto supone, correlativamente, que existan órganos de naturaleza política -por su designación, cometidos y responsabilidad-y órganos de composición técnica.

A partir de esta distinción estructural y estructurante deberá luego tomarse en consideración la existencia de órganos unipersonales versus órganos colegiados; en función de los cometidos deberá adoptarse por el legislador una u otra caracterización. Pero la diferenciación no acaba aquí, puesto que cabe incorporar al abanico de opciones otras alternativas, distinguiendo, por ejemplo, entre órganos centrales y órganos territoriales, o entre órganos departamentales y órganos transversales (los servicios centrales de adquisición de suministros y servicios constituyen un ejemplo de esta última posibilidad), o incluso, y cada vez con mayor frecuencia, planteando la necesidad de crear órganos específicos para la contratación de servicios comunes a diferentes Administraciones públicas, a partir de grandes centrales de compras o de pla- 
taformas electrónicas ${ }^{61}{ }_{i}$ lo que puede suponer elementos de transformación sustantiva, en este caso.

Por ello entendemos que el modelo actual no responde de manera adecuada al reparto constitucional de tareas. Es preciso superar la visión del órgano de contratación residenciado en el órgano superior de la Administración que entendemos es un residuo del régimen político anterior en el que no había lugar para la política inherente al pluralismo propio de la democracia. Es ciertamente cuestionable que los ministros y secretarios de Estado en la Administración general del Estado -o equivalentes en las comunidades autónomas-o los alcaldes y presidentes de las entidades locales deban ser en todo caso el órgano de contratación, sin perjuicio de que por razones de la cuantía en determinados casos sea necesaria la autorización del Consejo de Ministros o que en las entidades locales la mayor cuantía o duración suponga el traslado de la competencia al pleno de la entidad local ${ }^{62}$. Es tanto más sorprendente la consideración del ministro como órgano de contratación cuando la misma ley contempla la posibilidad de que se exceptúe esta previsión si se crea una junta de contratación cuya composición se establecerá por reglamento (una remisión al reglamento que tampoco parece muy adecuada) y luego, en relación a los miembros, una cuestión esencial para poder calificar la naturaleza de la instancia, sólo se precisa que deberá existir un funcionario que tenga atribuido el asesoramiento legal y un interventor ${ }^{63}$. El modelo decisional no parece demasiado consistente ni coherente con los principios constitucionales que disciplinan la organización y la actividad administrativa (art. 103 CE).

También debería tomarse en consideración la posibilidad de incorporar selectivamente en determinadas fases a representantes de organizaciones de consumidores y de empresarios; aunque esta sea una opción que deberá ponderarse muy detenidamente, y entiendo que sólo tiene cabida en determinados ámbitos sectoriales, como los procedimientos de preparación y adjudicación de contratos de gestión de servicios públicos en los que los usuarios podrían tener algún tipo de voz. De hecho, en los procedimientos de adjudicación que llevan incorporada una o varias fases o rondas de negociación (procedimientos negociados, diálogos competitivos o el nuevo procedimiento de la asociación para la innovación, introducido por las directivas comunitarias de 2014) la participación de los empresarios aparece como consubstancial al propio procedimiento.

61 Más allá de las referencias a la presentación electrónica de documentos, introducidas por el Real Decreto 814/2015, de 11 de septiembre, por el que se aprueba el Reglamento de los procedimientos especiales de revisión de decisiones en materia contractual y de organización del Tribunal Administrativo Central de Recursos Contractuales.

62 Ver art. 316 y Disposición Adicional Segunda, respectivamente, del TRLCSP.

63 Art. 316.4 TRLCSP. 
El correcto desarrollo de este rediseño funcional requiere separar los diferentes cometidos, puesto que la naturaleza de las decisiones así lo preconiza. Distinguir especialmente las distintas fases (que constituyen a su vez procedimientos autónomos): i) la previa o de preparación, ii) la de licitación y iii) la posterior de ejecución, y finalmente, iv) dentro de esta última cabría diferenciar la instancia que resuelve acerca del momento del pago, de la que previamente se pronuncia acerca del cumplimento efectivo y, según lo estipulado, de la tarea asignada en la adjudicación.

Así, a título ilustrativo cabe plantear también si es coherente que el mismo órgano que adopta todas las decisiones que constituyen la caracterizada como fase previa o de preparación, y que como tal tiene sustantividad propia y significa en todos los supuestos el ejercicio de una potestad discrecional, sea el mismo órgano que con posterioridad, en ejecución de lo delimitado inicialmente, adopte el abanico de decisiones que configuran el proceso de licitación y adjudicación, un ámbito este último en el que cabe entender que el ámbito de apreciación es muy limitado -pero no inexistente-, por lo que los tribunales reconocen este margen y solo anulan en el supuesto de error manifiesto en la apreciación.

El enunciado de la tipología de cuestiones a resolver en la fase caracterizada precisamente como previa -a la contratación, propiamente dicha- es ilustrativo del amplio margen de discrecionalidad que supone su realización.

Según una concepción muy extendida, y en buena parte debida al planteamiento del marco legal de la contratación, el expediente de contratación comienza con una decisión administrativa del órgano competente, generalmente el mismo que va a adjudicar después el contrato. Sin embargo, la lógica burocrática no debe hacer olvidar que, antes de esa decisión, puede y, en muchas ocasiones, debe existir una fase previa, "una fase previa a la preparatoria", si se admite la expresión, consistente en anunciar al mercado y a los potenciales interesados en los procesos de contratación las necesidades globales del órgano de contratación para un determinado ejercicio o período. Esos anuncios previos, que se pueden instrumentar mediante la publicación de avisos generales, de alertas puntuales o de calendarios de contratación, permiten informar a los mercados, facilitan su preparación, contribuyen a garantizar mejor la igualdad de oportunidades cuando los procesos de contratación se concreten después y, en definitiva, hacen más transparentes los procesos.

Con independencia de que haya existido o no esa fase de información, el procedimiento se inicia mediante la decisión motivada de las necesidades del contrato $^{64}$. Así, en primer lugar hay que determinar las necesidades a satisfacer, ello supone valorar distintas opciones, examinar diferentes alternativas, analizar los recursos disponibles -humanos y financieros-y su calidad. Se trata 
de determinar las necesidades que se pretende satisfacer mediante el recurso a operadores externos, a mecanismos de mercado. Esta es por su naturaleza la decisión de carácter más político y la que delimita el espacio en el que deberán desarrollarse las otras opciones, o mejor, los procesos que vendrán posteriormente. Por ello se exige que esté debidamente razonada y justificada con precisión, tanto acerca de la naturaleza y extensión de la necesidad que se pretende satisfacer mediante el contrato proyectado, como respecto de la necesidad del mismo para la mejor satisfacción y realización de los fines encomendados, como la idoneidad y contenido del objeto del contrato que se proyecta ${ }^{65}$.

Sin embargo, a pesar de que este pronunciamiento delimita el campo en el que se desarrollará posteriormente todo el proceso de la concreta y precisa contratación en cuestión, su relevancia parece desdibujarse y reducirse a un mero trámite formal, como si no tuviera una relevancia sustancial, puesto que la ley sólo indica que deberá quedar constancia en la documentación. No se obliga a darle publicidad específica, a pesar de que marca el terreno de juego, el ámbito en el que se desenvolverán todas las actuaciones y por consiguiente las condiciona. O quizás sería mejor señalar que las "debería condicionar", puesto que el análisis de algunos expedientes de contratación y la lectura de los Informes del Tribunal de Cuentas evidencian que esta decisión inicial, que -insistimos- condiciona todo el proyecto es objeto de escasa atención y está poco motivada. Un defecto que seguramente lastra la cadena de decisiones posteriores.

Quizás esta deficiencia tiene su origen en el hecho de que la sustantividad de la apreciación de las necesidades, su consideración específica, su relevancia como acto expresamente establecido por el legislador aparece por primera vez en la LCSP (2007); antes formaba parte de los arcanos de la Administración, de lo que se decía fuera de la luz, formaba parte del secreto. A pesar del tiempo transcurrido, los actores institucionales de la contratación pública no han asumido todavía su relevancia y significación práctica. El legislador no ha establecido hasta la fecha la obligación de publicar este acto de manera específica, careciendo de publicidad propia, lo que contribuye a generar opacidad acerca de una decisión de gran trascendencia y que debería poder ser objeto de debate y discusión pública. Un modo de proceder que no contribuye a mejorar la calidad de las decisiones públicas. A la novedad que supuso la introducción de esta exigencia -inspirada en el derecho francés- se añade que en la arquitectura de la ley no sólo se regula de forma separada (lo que podría ser coherente con su naturaleza), sino que su carácter preceptivo se establece en el dispositivo anterior al Libro relativo a la preparación de los contratos ${ }^{66}$. 
La aprobación del expediente previo es el segundo momento significativo de esta fase inicial, un momento determinante y que es consecuencia necesaria del proceso anterior, así como condición del posterior. Estos elementos deben estar relacionados por una secuencia lógica, deben constituir una cadena en la que progresivamente se vaya acotando la demanda que formula la Administración y a la que los licitadores deberán responder con sus ofertas respectivas. Se trata de aprobar el pliego de cláusulas administrativas particulares y las prescripciones técnicas ${ }^{67}$; dejando de lado la interdicción de definir un contenido que sólo pueda identificar un único destinatario, la trascendencia de esta decisión, la relevancia de su contenido es ineludible pues supone la concreción de la estrategia de la Administración compradora.

Esta decisión encuentra su complemento necesario en algunos supuestos en la determinación de las condiciones especiales de ejecución ${ }^{68}$. Notemos que este es un elemento esencial para la realización de las políticas sociales o medioambientales; no se trata de un aspecto estrictamente necesario (y de hecho, con anterioridad a su incorporación a las directivas europeas su formalización constituía una práctica muy rara en la contratación pública española), sino que responde a consideraciones sobre la apreciación de las necesidades ciudadanas y a la manera de satisfacerlas. Es pues una decisión que tiene un significado y contenido de carácter claramente político. Será el fruto de una apreciación discrecional en torno a la mejor manera de satisfacer el interés general.

De manera un tanto sorprendente, la regulación vigente sólo establece que la justificación de la elección del procedimiento ${ }^{69}$ y de los criterios que se tendrán en consideración para adjudicar el contrato deberán constar en el expediente; ${ }_{i}$ de nuevo vemos que no se exige una publicidad específica de dos elementos esenciales que condicionan toda la operación. Entendemos que estos dos aspectos constituyen ámbitos de libre decisión, y como tales deberían ser objeto de especial publicidad y transparencia a efectos de posibilitar el necesario y adecuado control por parte de los ciudadanos y de las empresas susceptibles de participar en la licitación. Una exigencia de publicidad que es coherente con la finalidad de la transparencia, pues esta reside en posibilitar el control, tiene un carácter marcadamente instrumental, no es un fin en sí mismo. Una publicidad o exteriorización de una decisión que constituye una garantía esencial para el correcto desarrollo de la contratación pública, para que esta contribuya eficazmente al correcto desarrollo del interés general que necesariamente debe impregnar toda decisión de los poderes públicos.

67 La relevancia de esta decisión justifica la reglamentación precisa establecida en los artículos 93 y siguientes TRLCSP.

68 Art. 118 TRLCSP.

69 De acuerdo con las disposiciones establecidas en las directivas europeas y desarrolladas en los artículos 138 y siguientes TRLCSP. 
No por casualidad el encabezamiento del capítulo en el que se configura el carácter de este trámite esencial tiene por título "Racionalidad y consistencia de la contratación del sector público", y el artículo 22 con el que se inicia, se titula "Necesidad e idoneidad del contrato y eficiencia de la contratación".

Con la aprobación de este conjunto de decisiones (que en la terminología de la LCSP aparecen como meros trámites burocráticos puesto que se presentan como "aprobación del expediente" ${ }^{70}$ y la aprobación de la decisión de abrir el procedimiento de adjudicación finaliza la fase de preparación, una fase que en los términos de la legislación española discurre en el interior de la Administración -en la opacidad-y que sin embargo por su contenido parece que debiera responder a un procedimiento de carácter más abierto y transparente. Publicidad que debería ser especialmente reforzada en aquellos supuestos en los que el contrato será de larga duración o con prestaciones especialmente complejas, como ocurre con algunas concesiones de obra pública-como las autopistas $^{71}$ - o con determinados contratos de colaboración público-privada que toman en consideración prestaciones de distinto carácter y naturaleza.

A pesar de la literalidad de lo estipulado, entendemos que una interpretación sistemática y constitucional evidencia que con este acto administrativo finaliza la parte del procedimiento de contratación que supone la adopción de decisiones fruto de la libre decisión de los órganos competentes (del "órgano de contratación", en términos del marco legal español). Un órgano de designación política y cuya legitimidad y responsabilidad es adecuada a esta significación. Esta configuración es coherente con la regulación contemplada en la nueva directiva que de manera explícita configura la libertad de los Estados miembros y sus Administraciones para escoger entre distintas opciones; un ámbito de decisión de carácter discrecional -decisión por ello siempre necesitada de una motivación suficiente y adecuada- que en la regulación de la última directiva (2014) adquiere toda su plenitud.

Las decisiones posteriores tienen otro carácter, una distinta naturaleza pues ya no se trata de elegir la manera más adecuada de satisfacer el interés general, ya no caben opciones en términos de oportunidad en función de las distintas preferencias. Se trata de ejecutar lo establecido, pero con decisiones que pueden suponer una cierta complejidad -en función del tipo de prestaciones-; en esta fase decisoria hay que valorar las ofertas y adjudicar el contrato de acuerdo con

70 La fase de preparación es más compleja en determinados contratos, así, por ejemplo en materia de obras requiere la elaboración, supervisión, aprobación y replanteo del correspondiente proyecto (arts. 121 ss. TRLCSP) o, en los contratos de concesión de obra pública, la realización de un estudio de viabilidad (arts. 128 ss. TRLCSP).

71 Sobre la importancia del programa económico y financiero, aspecto esencial para el correcto desenvolvimiento del equilibrio financiero del contrato y para la correcta delimitación de la asignación de los riesgos, ver, entre otras, la STS de 12 de mayo de 2016 (caso HENASA, concesionaria de la autopista de peaje R-2 de Madrid). 
los criterios preestablecidos. Una tipología de funciones que tienen necesariamente un contenido absolutamente técnico, que requieren de la aplicación de un conocimiento y un saber profesional y por ello quizás debieran atribuirse a un órgano de composición distinta. En especial si recordamos que la nueva directiva -todavía pendiente de transposición- tiene como objetivo simplificar y flexibilizar los procedimientos de adquisición de bienes y servicios (y de realización de obras). Un ámbito de decisión, de apreciación de las ofertas que no permite ya la adopción de opciones libres puesto que la misma está directamente vinculada por la demanda de la Administración -expresada en el complejo decisorio anterior-y las ofertas de los licitadores que concurren; un ámbito de decisión estrictamente vinculado por el principio competitivo que presupone la igualdad entre los distintos competidores.

Y en esta dirección, de diferenciar las características de los dos órdenes de decisiones, se pronunció la STS de 16 de diciembre de 2004. El Tribunal Supremo estableció claramente que la discrecionalidad juega con anterioridad a la adjudicación, en el momento de decidir cuáles son los criterios objetivos más significativos. Sin embargo, señaló la necesidad de respetar eso sí las reglas que impregnan la actual normativa sobre contratación pública: publicidad, libre concurrencia y transparencia administrativa, subrayando que no se puede ni se debe confundir la discrecionalidad de que pueda gozar la administración en la fijación previa de los distintos requisitos y criterios -así como de los baremos a considerar en su aplicación-, y un amplio abanico de especificaciones que constituyen las normas del concurso, frente a la ausencia de discrecionalidad en la asignación de la puntuación con arreglo a los distintos criterios prefijados en el pliego. Si bien, como hemos indicado anteriormente, en este último proceso de aplicación cabe un espacio valorativo para la apreciación de la realidad de las distintas condiciones; un margen de apreciación que sólo será cuestionado por el juez cuando se haya producido un error manifiesto en su ejercicio.

Sin embargo, esta toma en consideración de la distinta naturaleza de la decisión para asignarla a diferentes órganos no ha sido la opción del legislador español, ni de la doctrina. La solución tradicional por la que ha apostado el derecho administrativo español responde a otro modelo. El legislador español ha establecido un sistema que pivota sobre dos variables que aparentemente podrían funcionar de manera razonable, pero que en la práctica son poco realistas puesto que bajo la apariencia de una decisión que se predetermina de manera taxativa por los criterios previamente anunciados (y que deben desarrollarse en los correspondientes anuncios, pliegos de prescripciones técnicas o documentos descriptivos ${ }^{72}$ ) esconden que en la realidad de su aplicación, cuando hay que apreciar en qué medida se dan, en muchos supuestos hay un margen de apreciación que es imposible eliminar. Excepto, obviamente, 
cuando el único criterio a considerar para la adjudicación sea el del precio, el precio más bajo. En nuestra opinión, en este diseño institucional estriba la proliferación de casos de corrupción en materia de contratación; en todos ellos aparece un cargo electo o nombrados con criterios de confianza política participando de manera directa en la fase de apreciación pretendidamente técnica; un modo de proceder que suministra una apariencia de objetividad. En la mayoría de supuestos, este modo de proceder explica que la mayoría de supuestos enjuiciados por la jurisdicción penal no hayan sido previamente cuestionados ni ante la jurisdicción contencioso-administrativa ni, tampoco, por los correspondientes tribunales de cuentas.

Como hemos indicado, el tradicional remedio contra las malas prácticas en la contratación pública ha consistido en la pretensión de "objetivar" al máximo los criterios de valoración y así intentar que la aplicación se transforme en una operación mecánica, ello es posible en determinados supuestos y por esto existen programas de ordenador que pueden colaborar activamente en su ejecución. Esta idea se expresa en la regla según la cual se dará preponderancia a los criterios que puedan valorarse mediante cifras o porcentajes obtenidos mediante la mera aplicación de fórmulas establecidas en los pliegos, unos criterios que pueden ser objeto de evaluación automática por aplicación de las fórmulas, o que por el contrario requieran para su cuantificación de un juicio de valor $-y$ en este último supuesto debería constituirse un comité de expertos externos al órgano de contratación- ${ }^{73}$; y cuando se tome en consideración más de un criterio, deberá precisarse la ponderación relativa atribuida a cada uno de ellos o enumerarse por orden de importancia decreciente ${ }^{74}$. Curiosamente la exigencia de un comité de expertos ajeno al órgano de contratación no constituye una práctica habitual, a pesar de su exigencia legal, quizás porque (de nuevo) es una de las novedades introducidas por la LCSP de 2007. Nótese el carácter prescriptivo del requerimiento de "ajenidad" al órgano, puesto que este mismo requisito no es preceptivo en el formato tradicional que a continuación veremos.

El otro remedio -que ha tradicionalmente ha sido valorado de manera positiva- tiene un carácter orgánico, ya no se trata de incidir en la configuración de la "legalidad", de incrementar su densidad reduciendo espacios de libre decisión, sino de atender a quien debe decidir, una orientación hacia lo organizativo típica de los procesos en los que se atribuye un espacio de discrecionalidad, y sin embargo, como hemos enfatizado, ahora ya no estamos en ámbitos de discrecionalidad en sentido estricto. En coherencia con la complejidad que puede suponer la valoración de las ofertas y la apreciación de cuál sea la oferta económicamente más ventajosa -lo que no supone que sólo se tenga 
en consideración el precio-, consiste en atribuir dicha tarea a un órgano ad boc, la denominada "mesa de contratación"75. Este órgano es necesario en los procedimientos abiertos y restringidos y en los negociados con publicidad. En cambio, en aquellos procedimientos negociados en que no sea necesario publicar el anuncio de licitación ${ }^{76}$, la creación de la mesa será potestativa; un régimen que en nuestra opinión es todavía más sorprendente pues priva de elementos de control a un tipo de procedimiento que por sus características de opacidad puede ser recipiendario de malas prácticas.

Curiosamente, el cometido de este órgano se califica por el legislador como de "asistencia" al órgano de contratación, a pesar de que se le encomienda la tarea fundamental, que es la de examinar las ofertas, valorarlas -y apreciar su consistencia, coherencia, racionalidad-y, aplicando los criterios previamente establecidos y publicados, formular la propuesta de adjudicación. Si bien esta propuesta no genera derechos en favor del licitador propuesto, tiene una significación jurídica y un valor, pues su rasgo más relevante es que vincula limitadamente al órgano de contratación en la medida en que, si este decide no seguirla, deberá motivar la decisión de apartarse ${ }^{77}$; entendemos que la carga de motivación en este supuesto implica que el contenido de la motivación deberá estar directamente relacionado con las razones que justifican o fundamentan la posición del órgano de contratación, pues la exigencia general del deber de motivar la adjudicación está expresamente establecida con carácter general (art. 154.3 TRLCSP). Esta articulación de atribuciones responde a la regla en virtud de la cual la titularidad de la competencia para adjudicar es (todavía en el derecho positivo) del órgano de contratación, a cuyas características nos hemos referido anteriormente, pues es siempre el máximo responsable de la Administración o departamento en cuestión y por lo tanto un cargo electo o designado con criterios de confianza política).

Dada la especial trascendencia y significación de la labor que desempeña la denominada "mesa de contratación", una tarea caracterizada por el reconocimiento de un margen de apreciación que la jurisprudencia ha calificado reiteradamente como "discrecionalidad técnica", la legislación exige que la adjudicación posterior (por parte del órgano de contratación) deba ser en todo caso motivada y contener la suficiente información para que permita al licitador descartado interponer un recurso fundado ${ }^{78}$. El contenido y alcance de esta motivación ha sido objeto de controversia pues hasta fechas recientes el Tribunal Supremo aceptaba que pudiera consistir en calificaciones expresadas de manera numérica, sin necesidad de explicitar el razonamiento que habría 
conducido a la mencionada cifra, sin embargo, esta motivación debe revestir unas características especiales, como la jurisprudencia ha empezado a indicar recientemente al establecer que "es necesario que la justificación o explicación que es inherente a la necesaria motivación incluya estos dos elementos inexcusables: (a) los singulares criterios de valoración cualitativa que se han seguido para emitir el juicio técnico; y (b) las concretas razones por las que la aplicación de esos criterios valorativos conduce, en el ejercicio realizado por cada aspirante, a la concreta puntuación y calificación aplicada"79. En esta misma dirección de exigir mayor transparencia a la decisión, partiendo del carácter garantista que la misma supone al posibilitar un mayor control, los tribunales de recursos contractuales exigen comunicar los elementos determinantes de la adjudicación al resto de concursantes (en aplicación del art.154.4.c TRLCSP).

Dada la relevancia práctica de la "mesa de contratación" no se conocen las razones por las que el legislador no ha establecido de manera clara y precisa los criterios que debieran orientar su composición, no parece suficiente argumentar que la organización es una materia reservada constitucionalmente a las comunidades autónomas pues las garantías comunes en materia de régimen jurídico y de procedimiento administrativo son competencia del legislador estata ${ }^{80}$, y así lo ha entendido al establecer las reglas esenciales relativas a los tribunales administrativos de recursos contractuales (art. 41.3 TRLCSP). Por ello, el estado actual del derecho aplicable obliga a plantear la cuestión de si está correctamente diseñada la composición de las mesas de contratación. En efecto, el legislador se ha limitado a establecer dos elementos que le dotan de una determinada caracterización: i) quién tiene la competencia para nombrar a los miembros del órgano colegiado en cuestión y asigna esta responsabilidad al órgano de contratación, ii) la existencia necesaria de unos determinados perfiles: entre los vocales deberán figurar necesariamente un funcionario que tenga legalmente asignadas tareas de asesoramiento jurídico y un interventor. Así como otros dos elementos complementarios: i) el número de vocales se determinará reglamentariamente, pero no se expresa quién dictará este reglamento $_{i}$ ii) el secretario deberá ser nombrado entre funcionarios o personal dependiente del órgano de contratación, no estableciéndose ningún requisito para prefigurar las condiciones que debería reunir el presidente del órgano. Es pues factible, y de hecho así sucede en numerosas ocasiones, que el presidente sea el alcalde o presidente de la entidad local ${ }^{81}$-u otro cargo electo en quien delegue-, o que en las comunidades autónomas sea un consejero o cualquier cargo nombrado por razones de confianza (política), como un director genera;

81 En relación con las competencias de los órganos locales, alcalde y pleno, así como acerca de la posibilidad de crear "juntas de contratación" sustitutivas de las "mesas de contratación", ver la Disposición Adicional Segunda del RDLCSP. 
y si la contratación la realiza un organismo público, puede ser el presidente del ente (que es normalmente el órgano de contratación).

Vemos pues que el legislador se ha limitado a establecer unas reglas muy básicas, un haz de características que dibujan un órgano con unas tareas meramente de soporte técnico o asistencia al órgano decisorio. La escasa condicionalidad que ha establecido el legislador no es adecuada para los cometidos asignados, valorar las ofertas y realizar la propuesta de adjudicación. Una propuesta que, como hemos visto, supone realizar una valoración, una apreciación en la que necesariamente existe un margen que puede conducir a un resultado concreto que dependa de las cualidades personales de cada sujeto interviniente, sin que este posible sesgo deba entenderse de manera forzosa como una patología, sino como el ejercicio de la capacidad de interpretar y aplicar los criterios establecidos. Por ello, precisamente, el órgano debe tener un carácter colegial, para neutralizar la posible subjetividad derivada de un juicio que puede depender de razones personales -experiencia previa, formación específica, trayectoria personal y profesional, etc.-.

La apreciación debe responder a criterios técnicos, no políticos o discrecionales, y, como corolario de este tipo de juicio, el control judicial será limitado. Como reiteradamente ha indicado la jurisprudencia del Tribunal Supremo, los órganos administrativos a quienes corresponde la valoración de en qué medida concurren determinados elementos fácticos gozan de un cierto margen de discrecionalidad en su apreciación que merece la calificación de técnica y no revisable jurisdiccionalmente en lo que se refiere a los juicios que la Administración emita acerca de la apreciación de los elementos aportados; pero ello no excluye el que los tribunales puedan controlar la concurrencia de los límites generales jurídicamente impuestos a la actividad discrecional no técnica de la Administración que se refieren a la competencia del órgano, procedimiento, hechos determinantes, adecuación al fin perseguido y al juego de los principios generales del derecho; entre los que, en estos casos, cobran especial interés los de mérito y capacidad expresamente señalados al efecto por el artículo $103 \mathrm{CE}^{82}$. Pues los principios de mérito y capacidad cumplen una finalidad de relevancia constitucional que cobra especial significación en materia de contratación pública, son garantía de la objetividad e imparcialidad de la acción administrativa.

Atendiendo a estas consideraciones parece que el legislador hubiera tenido que adoptar una regla equivalente a la que se estableció en el Estatuto Básico del Empleado Público (2007) para la formación de los órganos de selección del personal de las Administraciones públicas, puesto que la apreciación o

82 En la dirección apuntada por la STS de 17 de diciembre de 2012 que anula una adjudicación por insuficiencia de motivación al no haber existido una apreciación propia por parte de la mesa de contratación, el órgano que debe efectuar la valoración de las ofertas de los licitadores y la propuesta de adjudicación. 
juicio de valor que realizan estos órganos colegiados en relación a las capacidades de los aspirantes tiene el mismo carácter que la que realizan las mesas de contratación. Así, de acuerdo con lo establecido por el legislador ${ }^{83}$ : i) la composición de estos órganos colegiados deberá ajustarse a los principios de imparcialidad y profesionalidad de sus miembros; ii) el personal de elección o de designación política, los funcionarios interinos y el personal eventual no podrán formar parte de los órganos de selección, iii) la pertenencia a estos órganos será siempre a título individual, no pudiendo ostentarse en representación o por cuenta de nadie ${ }^{84}$.

Los miembros de la "mesa de contratación" no sólo son nombrados discrecionalmente por el órgano de contratación sin que sea exigible ningún requisito especial de capacidad o idoneidad, sino que posteriormente en el ejercicio de sus funciones no solo no se garantiza que actúen con independencia funcional en el ejercicio de su cometido -no hay una prohibición de impartir instrucciones, ni de solicitarlas-, sino que el propio presidente puede tener una posición de superioridad jerárquica en relación con los otros miembros del órgano; si bien debería entenderse que ello es contrario a las funciones propias de la presidencia establecidas con carácter general en la legislación de régimen jurídico y procedimiento administrativo común ${ }^{85}$, no puede ignorarse que esta posición puede ser inherente al poder de nombramiento. Y, de acuerdo con una interpretación literal del RDLCSP -que hasta la fecha ha sido dominante-, podemos encontrar, en el entorno institucional de la administración instrumental de la $\mathrm{AGE}^{86}$, de las Administraciones de las comunidades autónomas y de las entidades locales, presidentes de las mesas de contratación que tienen la condición de electos o designados según criterios de confianza política (como ocurre con los directores generales de las Administraciones autonómicas). En nuestra opinión este cuadro no es acorde con las exigencias constitucionales propias del Estado de derecho y los tribunales deberían exigir una depurada composición de estas instancias que, como hemos visto, son determinantes ${ }^{87}$ en el proceso de adjudicación.

84 La finalidad de esta disposición era impedir la representación de representantes de los sindicatos en los órganos de selección del personal.

85 Artículo 23 LRJPAC que permite dirimir con el voto del presidente los supuestos de empate. Aunque cabe señalar que el artículo 22 de esta misma ley sólo sustrae de la estructura jerárquica los órganos colegiados en los que participen organizaciones sociales (art. 22.2).

86 Administración General del Estado; la tipología de organismos está regulada en la actualidad en la Ley 6/1997, de organización y funcionamiento de la Administración general del Estado, que será próximamente derogada al entrar en vigor la Ley 40/2015, de régimen jurídico del sector público.

87 Utilizamos la noción de "determinantes" que ha irrumpido en el derecho de las evaluaciones ambientales - de la mano del derecho europeo- para expresar el valor de una decisión en el marco de un procedimiento complejo, más allá de la dicotomía tradicional en el derecho 
Por último, cabe preguntarse también si, dadas las características técnicas que necesariamente debe tener la decisión de adjudicar el contrato a la empresa que ha presentado la oferta económicamente más ventajosa, es adecuada a la distinción constitucional entre Gobierno y Administración la atribución de esta responsabilidad a un órgano de contratación como el actual. Parece que sería más coherente que la decisión final, que necesariamente se enmarcará en la estrategia definida en la fase previa por un órgano -esta vez sí- de naturaleza política, la adoptara una instancia con una composición y sometida a unos criterios de actuación que garantizaran de manera fehaciente que no se producen interferencias en el proceso decisorio.

Por ello parece que sería razonable dotar al órgano en cuestión no sólo de una mayor profesionalidad y saber hacer, sino también de una mayor estabilidad. También, para evitar determinados fenómenos de captura que a veces la permanencia puede inducir, sería conveniente que se articulasen mecanismos que posibilitan una cierta rotación -parcial y cada cinco o seis años, p. ej.-, siguiendo las mejores prácticas que podemos encontrar en otros entornos institucionales.

Reforzar la profesionalidad de las estructuras que realizan compras públicas puede desarrollarse mediante la introducción de reglas que de manera prescriptiva definan los requisitos organizativos y profesionales que la acreditan para realizar la tarea. Y también existen vías complementarias, procesos de acreditación basados en la evaluación continua de la existencia de los requisitos profesionales y organizativos necesarios. Se debería entonces pensar en quién podría realizar esta función de acreditación, que en todo caso debería ser una instancia independiente de las Administraciones contratantes. A nivel internacional existen experiencias conocidas y consolidadas, quizás la más reputada es la del National Institute of Governmental Purchasing (NIGP), fundado en los años 1940, que reagrupa a 2.700 agencias de public procurement en Estados Unidos y Canadá que actúan en representación de unos 17.000 compradores públicos y que se ha dotado de un ente independiente, el Universal Certification Council, que expide los certificados de calidad que atestiguan la competencia profesional de los participantes (p. ej., el Certified Professional Public Buyer).

En esta dirección de incrementar el profesionalismo como vía para reforzar la integridad de las Administraciones públicas y prevenir la corrupción puede también considerarse la experiencia de algunos países europeos que han creado agencias especializadas que realizan adquisiciones públicas de manera centralizada (Alemania y Francia y, en menor medida, Italia). 


\section{INCREMENTAR EL CONTROL GARANTIZANDO UNA PUBLICIDAD Y TRANSPARENCIA ADECUADA Y REFORZANDO LAS INSTITUCIONES DE SUPERVISIÓN}

Como señalan los especialistas más reconocidos, lo más fácil es introducir medidas represivas o sancionadoras -reformas del Código Penal, como se ha hecho en España-, olvidando que cuando interviene el Código Penal el daño ya está causado (y los requerimientos para imponer sanciones en este orden pueden generar trabas que acaben facilitando la impunidad ${ }^{88}$ ), cuando, por el contrario, una política de integridad debería inclinarse por la prevención ${ }^{89}$ y la mejora de las reglas, estructuras y procesos.

Una política de prevención requiere de la adopción (y en su caso de la mejora) de la infraestructura decisional en los sectores especialmente sensibles; y sin duda alguna, la contratación pública es uno de ellos. Sin embargo, en estos últimos años, a pesar de la eclosión de casos de corrupción vinculados a la contratación pública no se han adoptado medidas de reforma del marco legal de la contratación pública ni se ha procedido a un análisis de las deficiencias del marco legal vigente. Sólo se han producido modificaciones sustanciales en la tipificación de los delitos y las penas en el Código Penal y se han introducido puntuales modificaciones del régimen de transparencia de los contratos al reforzar la información que debe constar en los portales. Si bien la aprobación de la Ley de Transparencia, acceso a la información pública y buen gobierno (2013) no ha supuesto tampoco un salto cualitativo en la información disponible para el público, especialmente en materia de contratación, puesto que la información que debe ser publicada obligatoriamente por la Administración es la misma que ya era objeto de publicación en el denominado perfil del contratante o en los boletines oficiales. Aunque tampoco puede desconocerse la dinámica que ha generado la adopción de la Ley de 2013, pues en la actualidad crecen las peticiones de información al amparo del nuevo derecho desarrollado por la ley ${ }^{90}$. Periodistas, miembros de los gobiernos locales en la oposición y asociaciones están planteando importantes requerimientos de documentos, actas de reuniones, agendas, que suponen una apertura notable en unas Administraciones que todavía funcionaban en un entorno en el que el secreto era la regla y

Ver, en este sentido, el reciente Auto del Tribunal Supremo de 28 de abril de 2016 que sobreseía provisionalmente la acusación presentada contra una antigua alcaldesa de Jerez por no reunirse los requisitos subjetivos exigidos para la existencia del delito de prevaricación. Este caso afecta a contratos de servicios adjudicados en el marco de la denominada "trama Gürtel", uno de los casos de mayor corrupción destapados hasta la fecha y que afecta a un gran número de comunidades autónomas y gobiernos locales que fueron gobernadas por el Partido Popular.

89 Cerrillo (2011).

90 Arts. 12 ss. Ley 19/2013. 
la publicidad la excepción (en cuanto limitada a los procedimientos en curso y para los interesados). La creación de una instancia administrativa de tutela del derecho está apoyando fuertemente este cambio cultural ${ }^{91}$.

Cuando Rosanvallon, en su obra más reciente ${ }^{92}$, se planteaba cómo responder ante la desafección y la cólera de los ciudadanos que está creciendo en los sistemas democráticos, respondía señalando que la democracia hasta ahora sólo ha significado que el poder político responde a la legitimidad derivada de las urnas, sin que, a pesar del aumento considerable del poder residenciado en el ejecutivo, se haya democratizado la acción gubernamental, puesto que esta no obedece a reglas de transparencia, de ejercicio de la responsabilidad y rendición de cuentas o de reactividad a las demandas de los ciudadanos claramente establecidas. Como él mismo recuerda, las cuestiones de corrupción han estado en el corazón de la reflexión política desde la Antigüedad, pero lo nuevo es que en la actualidad la demanda de integridad adquiere una mayor relevancia y significación (habiéndose pasado de la política de programas a la política de personas ${ }^{93}$ ). En este contexto, para recuperar la confianza se genera el deber de transparencia de los gobernantes y se crean instituciones para garantizar la integridad ${ }^{94}$.

No podemos ahora examinar el papel de estas instancias en la vigilancia y supervisión de la contratación pública, sólo cabe destacar que su cometido se fundamenta en una mayor publicidad de las actuaciones (procedimientos y decisiones) y de los documentos (expediente).

En esta dirección, el legislador debería garantizar un escrutinio público de todo el procedimiento, puesto que la contratación pública no es una cuestión privada, con las excepciones estrictamente necesarias en aquellos supuestos en que la confidencialidad de determinados documentos sea necesaria para proteger el secreto comercial o el correcto funcionamiento de la competencia -como sucede con las ofertas presentadas por las empresas en una licitación-. La contratación on line puede favorecer esta apertura. Ello supone el carácter público, abierto y accesible de todo el procedimiento, de toda la documentación que lo soporta, del expediente; la Administración debería tener la obligación de publicar -publicación activa- ${ }^{95}$ y no sólo de garantizar el derecho

91 Ver arts. 33 ss. Ley 19/2013.

92 Rosanvallon (2015).

93 Ver (ibíd., p. 353); en los capítulos iniciales plantea el fenómeno de la personificación de los ejecutivos frente al modelo anterior de la colegialidad.

94 Ver, en Francia, la Haute Autoritépour la transparance de la vie publique (2013); en Italia, el cambio de modelo que ha supuesto la creación de la Autorità Nazionale anticorruzione (2014), o en Catalunya, la creación de la Oficina Antifrau de Catalunya (2008).

95 La Ley 19/2013, de transparencia, acceso a la información pública y buen gobierno, no satisface los cánones actuales y parece todavía anclada en la vieja tradición de la publicidad puntual de algunos actos administrativos. Y lo mismo ocurre con las distintas leyes 
de acceso -que impone una carga a los particulares-, pues ello posibilita un amplio control por parte de los medios de comunicación y los ciudadanos. La publicidad debería abarcar la decisión de adjudicación, más allá de un resumen de las razones que justifican la elección, y también debería publicarse íntegramente el contrato (como sucede ya en algunos países de la Unión Europea, como Suecia), no sólo el objeto, el nombre de la empresa y la cuantía (que es lo que hasta la fecha se requiere), con la salvedad de aquella información que pudiera tener carácter confidencial o tener un efecto anticompetitivo-como puede ocurrir con los contratos de muy corta duración-.

Incrementar la publicidad tiene como fin esencial ampliar las posibilidades de control, pero para ello sería también necesario ampliar la legitimación para impugnar las decisiones relevantes (aquellas que actualmente ya son susceptibles de impugnación mediante el recurso especial) por parte de un abanico más amplio de sujetos, como las asociaciones de consumidores o asociaciones de empresarios, colegios profesionales, las denominadas cámaras de contratistas, etc., más allá del amplio reconocimiento que la legitimación por intereses colectivos ya tiene en nuestro ordenamiento. Se trata de introducir en el campo de la contratación pública una legitimación en interés de la legalidad ordinaria, circunscrita a un círculo de actores interesados por razón de su objeto social.

Sin perjuicio de reconocer una legitimación más activa a los licitadores no adjudicatarios para interponer el recurso especial en materia de contratación frente a la resolución de la adjudicación, puesto que, una vez el legislador ha reconocido que cabe la legitimación por interés cuando este se haya visto perjudicado -y no sólo por afectación a un derecho- ${ }^{96}$, no parece acorde con el derecho a la tutela judicial efectiva (que obliga a realizar una interpretación antiformalista, según la jurisprudencia del Tribunal Constitucional) y con el cometido propio de la jurisdicción contencioso-administrativa ${ }^{97}$ que los tribunales administrativos de recursos contractuales exijan para recurrir que el interesado haya quedado en una posición que le permita beneficiarse de la anulación, en su caso, de la adjudicación ${ }^{98}$. Esta restricción de la legitimación activa de los licitadores (que han participado ya en un procedimiento previo) no es acorde con las finalidades y objetivos que el derecho europeo de la contratación perseguía mediante la creación de un recurso ágil y eficaz de tutela de los licitadores; argumentar que no se pretende disponer de una legitimación universal garante de la legalidad objetiva no es suficiente en este contexto, y es sobre todo contrario a la voluntad del legislador europeo de la

de las comunidades autónomas que han seguido la misma estela, como la Ley 19/2014, de transparencia, acceso a la información pública y buen gobierno de Catalunya.

98 Ver, entre otras, Resolución del Tribunal Central de Recursos Contractuales 260/2013. 
contratación pública que constituye la fuente de la que traen causa los tribunales administrativos contractuales ante los que cabe plantear el recurso especial ${ }^{99}$.

El planteamiento de la legislación española de contratos en relación con el recurso especial en materia de contratación ha sido hasta la fecha muy cicatero. Se ha demorado en exceso, y sin justificación alguna, la implantación del mecanismo, de modo que sólo a partir de la reforma de 2010 puede hablarse de un instrumento homologable en términos de directivas de recursos; aun así, se sigue limitando el recurso especial a los grandes contratos (grandes por cuantía), consagrando una discriminación en términos de garantía para los interesados difícil de sostener, y además se mantienen unas restricciones de legitimación (solo las personas físicas o jurídicas cuyos derechos o intereses legítimos se hayan visto perjudicados o puedan resultar afectados por las decisiones objeto de recurso) que tampoco resultan convincentes.

Además, la configuración de los propios órganos competentes parece hasta la fecha poco meditada: por una parte, opciones en favor de órganos unipersonales han tenido que ser rectificadas ante el volumen y la complejidad de las cuestiones objeto de litigio; por otra parte, la necesaria e ineludible garantía de especialización, dedicación exclusiva e independencia no siempre se ha conseguido, y se ha puesto severamente en cuestión cuando se han planteado alternativas consistentes en atribuir la función resolutoria en materia de recurso a órganos preexistentes con otro tipo de funciones (fundamentalmente consultivas).

Los órganos de control interno de la gestión económica y financiera son una pieza clave en el control de los procesos de contratación pública. Sin embargo, la tradicional distinción entre el régimen de fiscalización previa de los actos con contenido económico (aplicable, en general, a la Administración y a los organismos sujetos a derecho administrativo) y el régimen de auditoría o fiscalización "a posteriori" (de aplicación al sector público vinculado o dependiente sometido al derecho privado), que se ha mantenido vigente durante años, aparece hoy en día claramente superada por una realidad cada vez más compleja, que pone en evidencia tanto las limitaciones como la inoperancia de ambos regímenes a la hora de garantizar la correcta utilización de los fondos públicos en la contratación administrativa. Así, la fiscalización se ha convertido en un trámite cada vez más formal y rigorista, cuando no estrictamente de legalidad, mientras que la auditoría "a posteriori", en ocasiones externalizada, se ha mostrado claramente insuficiente para reparar situaciones de hecho o anomalías producidas, cuando no inservible desde la perspectiva del control de eficacia y eficiencia del gasto público.

Se impone, pues, un replanteamiento global de la función de control, en aras de asegurar no solamente, y para todo el sector público sin distinción, la 
adecuación de los actos y trámites del proceso contractual a la legalidad, sino también la gestión eficiente y la satisfacción de los intereses públicos.

En una línea de razonamiento similar a la que se ha expuesto respecto del control interno a cargo de la Intervención, se impone también la revisión del funcionamiento de los órganos de control externo en relación con la contratación. Dos son los aspectos cruciales en este punto: por una parte, se trata de garantizar que el control externo se pueda practicar con la mayor proximidad posible en el tiempo a la realización de la actividad objeto de fiscalización, frente a los retrasos clamorosos que se observan a menudo y que convierten el dictamen de los tribunales de cuentas prácticamente en un producto de curiosidad histórica; por otra parte, se trata de asegurar que las conclusiones y recomendaciones de dichos tribunales sean de estricta observancia, vinculen efectivamente al órgano o ente afectado y se haga un seguimiento efectivo de las mismas para detectar los casos de incumplimiento, que deberían ser además objeto de sanción.

\section{A MODO DE CONSIDERACIONES FINALES}

Como han señalado recientemente Villoria e Izquierdo, conocemos que los incentivos, las oportunidades y los riesgos pueden provocar conductas inmorales hasta en personas decentes, por ello es preciso establecer normas, procesos y órganos dentro de cada organización pública que prevengan conductas inmorales y promuevan la integridad ${ }^{100}$.

La legislación relativa a la contratación pública ha cumplido tradicionalmente, aunque quizás de manera insuficiente, este cometido.

El derecho administrativo español pertenece al limitado número de sistemas jurídicos que cuentan con la institución del contrato administrativo, un contrato que se diferencia del contrato civil por el ejercicio de las prerrogativas exorbitantes de la Administración relativas a la ejecución y a la resolución. La paradoja existente consiste en que si bien el derecho positivo estableció distintos procedimientos para la adjudicación de contratos -garantes de la correcta asignación de los recursos públicos-, la doctrina centró sus análisis en la faceta de carácter más dogmático -el fundamento y la naturaleza del instituto del contrato administrativo-, descuidando aquellos aspectos relativos al proceso de formación de la voluntad que sin embargo son cruciales para garantizar la integridad en la contratación pública y evitar el fraude que supone la corrupción. En el pasado la finalidad de la doctrina era limitar el ejercicio de las prerrogativas, luchar contra el poder y sus inmunidades; ahora se trata de garantizar que se ejerzan efectivamente los poderes de la Administración, 
que en la realización de sus cometidos actúe al servicio del interés general y asignando los fondos públicos de manera eficiente.

La influencia del derecho europeo, centrado en los procedimientos de adjudicación y la garantía de la libre competencia de los contratos públicos -aspectos todos ellos relacionados con la posición de poder que tiene en el mercado la Administración-, ha hecho que cambiara el centro de interés de la doctrina, produciendo análisis sobre las debilidades del sistema legal, especialmente en sus desajustes con el derecho europeo. Al centrar la atención en las cuestiones relativas al proceso decisorio, la tipología de los órganos y su necesaria correlación con las funciones, surgen nuevas perspectivas que permiten ajustar de manera más adecuada a los postulados constitucionales el reparto de tareas entre órganos. En esta dirección reforzar el profesionalismo aparece como una vía necesaria para prevenir la corrupción.

En la actualidad, la eclosión de casos de corrupción originados por malas prácticas en todo tipo de contratos (obras, servicios, suministros) induce a plantear la necesidad de acometer una reforma en profundidad que altere algunos de los supuestos sobre los que hasta la fecha ha funcionado la arquitectura institucional. Es cierto que algunos nuevos instrumentos de centralización de la adquisición de suministros y servicios están transformando de manera silenciosa las estructuras de compras públicas, pero también es cierto que el sistema decisional reposa sobre algunos apriorismos alejados de la realidad. Entendemos que es preciso asumir que en la contratación pública -de manera variable en función de los ámbitos objetivos y de las cuantías- existen espacios de libre decisión y ámbitos en los que cabe un margen de apreciación. En consecuencia, no cabe residenciar todo el control en su vertiente jurisdiccional, se deben crear nuevas instancias o dotar a las existentes de mayores medios. Y muy especialmente, es preciso abrir la contratación pública a la luz del sol para permitir que los ciudadanos, los consumidores, los competidores, etc. controlen más y mejor a los podres públicos.

\section{BIBLIOGRAFÍA}

ASTRID. (2015). La nuova disciplina dei contratti pubblici: le regole, i controlli, il processo. Roma.

BARRERO RodríGueZ, C. (2007). La resolución de los contratos administrativos por incumplimiento del contratista. Valladolid: Lex Nova.

BAÑO, J. M. (2013). Del ius variandi a la libre concurrencia: la prohibición de modificación como regla general de los contratos públicos. Anuario de Gobierno Local. 2012, IDP, Barcelona.

BACIGALUPO, M. (1997). La discrecionalidad administrativa (estructura normativa, control judicial y límites constitucionales en su atribución). Madrid: Marcial Pons. 
Byung-Chul, H. (2014). La sociedad de la transparencia. Barcelona: Herder.

Canabes, C. y B. Neveu. (2008). Droit de la concurrence dans les contrats publics. Paris: Le Moniteur.

Cerrillo, A. (2014). El principio de integridad en la contratación pública. Cizur Menor: Thomson Reuters-Aranzadi.

Cerrillo, A. (2011). Transparencia administrativa y lucha contra la corrupción en la administración local. Anuario de Gobierno Local. Barcelona, IDP/Fundación de Gobierno Local.

Díez Sastre, S. (2012). La tutela de los licitadores en la adjudicación de contratos públicos. Madrid: Marcial Pons.

FERNÁNDEZ DE VELASCO, R. (1927). Los contratos administrativos. Madrid: Librería general de Victoriano Suárez.

Gallego Córcoles, I. (2015). "La modificación de los contratos en la cuarta generación de directivas sobre la contratación pública". Ponencia presentada en el X Congreso de la AEPDA, Madrid, febrero. En curso de publicación en las Actas del Congreso, accesible en la web de la AEPDA.

García de Enterría, E. y Fernández Rodríguez, T. R. (2008). Curso de Derecho Administrativo (I). 14. ${ }^{\text {a }}$ ed. Cizur Menor: Thomson-Civitas.

GARCía MACHO (ed.). (2014). Ordenación y transparencia económica en el derecho público y privado. Madrid: Marcial Pons.

Gimeno Feliú, J. M. (2014). El nuevo paquete legislativo comunitario sobre contratación pública. De la burocracia a la estrategia. Cizur Menor: Thomson-Aranzadi.

Gimeno Feliú, J. M. (2015). La reforma comunitaria en materia de contratos públicos y su incidencia en la legislación española: Una visión desde la perspectiva de la integridad. Ponencia presentada en el Congreso de la AEPDA, Madrid. En curso de publicación con las Actas del Congreso, accesible en la web de la AEPDA.

Hernando Rydings, M. (2012). La colaboración público privada. Fórmulas contractuales. Madrid: Thomson Reuters/Civitas, especialmente pp. 375 ss.

Horgué Baena, C. (1997). La modificación del contrato administrativo de obra. Madrid: Marcial Pons.

Jimenéz Asensio, R. (1992). Política y Administración: los puestos de designación política en las Administraciones Públicas. RVAP, p. 32. 
JimenÉz DE Cisneros, F. J. (1998). Obras públicas e iniciativa privada. Madrid: Montecorvo.

Lozano Cutanda, B. y Soriano, J. E. (2011). "La Guía de la Comisión Nacional de la Competencia sobre contratación pública y competencia". Contratación administrativa práctica, 108, pp. 48 ss.

Malaret, E. (1996). Público y privado en la organización de los Juegos Olímpicos de Barcelona 1992. Madrid: Civitas.

MALARET, E. (1997). Le service public dans l'experience espagnole. AJDA.

Malaret, E. (2003). Autoridades independientes y justicia administrativa. En MonTORO Chiner, M. J. (coord.). La justicia administrativa. Libro Homenaje al Prof. Dr. D. Rafael Entrena Cuesta. Barcelona: Atelier.

Malaret, E. (2003). Financiación e infraestructuras de las televisiones. Revista Vasca de Administración Pública, 65, p. 1.

Malaret, E. (2003). Partenariato pubblico-privato: finanziamento delle infrastrutture e gestione dei servizi pubblici locali in Spagna. Servizi pubblici e appalti.

MARTín Rebollo, L. (2015). Notas introductorias al TRLCSP. Leyes administrativas. Manual y normas básicas. Cizur Menor: Civitas/Aranzadi/Thomson Reuters.

Martin-Retortillo, S. (1960). El derecho civil en la génesis del derecho administrativo y sus instituciones. Sevilla: Instituto García Oviedo.

OCDE, V. (2009). L'intégritédans les marchés publics. Les bonnes pratiques de Aà Z. Paris, 2007. Trad., La integridad en la contratación pública. Buenas prácticas de la A a la Z, Madrid: INAP.

PARADA, R. (1963). Los orígenes del contrato administrativo en el derecho español. Sevilla: Instituto García Oviedo.

RACCA, G. M. (2015). Dall'Autorità sui contrati pubblici all'Autorità nazionale anticorruzione: il cambianto del sistema. Ponencia presentada en el Congreso sobre la "Nueva disciplina de los contratos públicos entre exigencias de simplificación, impulso de la economía y lucha contra la corrupción". Varenna. En curso de publicación, accesible en la web de la Fundación ASTRID.

Rosanvallon, P. (2015). Le bon gouvernement. Paris: Seuil.

Ruiz OjedA, A. (2006). La concesión de obra pública. Madrid: Thomson-Civitas.

Villoria, M. (2014). Hacia una comprensión de la corrupción en España. Working paper 1/2014. Transjus: Universidad de Barcelona. 
Villoria, M. e IzQuierdo, A.. (2015). Ética pública y Buen Gobierno. Madrid: Tecnos.

Texto Refundido de la Ley de Contratos del Sector Público (TRLCSP):

Art. 3

Art. 19.1.a.

Art. 19.3.

Art. 22.

Arts. 40 a 49 .

Art. 109.

Art. 118.

Art. 150.2.

Art. 150.2 .

Art. 150.4 .

Art. 160 .

Art. 316 y Disposición Adicional segunda.

Art. 316.4 .

Art. 320 